\title{
Personality and Economic Choices
}

\section{Christopher Boyce ${ }^{1}$, Mikołaj Czajkowski ${ }^{2}$ and Nick Hanley ${ }^{3}$}

\begin{abstract}
:
There is substantial variation in individual preferences for public goods, yet much of that variation remains poorly understood. However, simple measures of personality can help to explain economic values and choices in a systematic way. In this paper, we examine the effects of personality on individual economic choices over public environmental goods. Based on three datasets from three separate stated preference studies, we use a hybrid choice econometric framework to examine the effects of personality on preferences for the status quo, changes in environmental quality, and costs of investing in environmental improvements. We find effects that are consistent across all datasets. Personality, a stable feature of an individual's character that is simple to measure, enriches explanations of why the demand for environmental goods varies across people, provides an indication of how different people are likely to react to the introduction of environmental policies, and explains substantial differences in Willingness to Pay.
\end{abstract}

Keywords: personality, preference heterogeneity, hybrid choice models, stated preferences, choice models.

JEL codes: C35, D03, D12, D61, Q25, Q51

Revision for JEEM, June $29^{\text {th }}$

\footnotetext{
${ }^{1}$ University of Stirling, Stirling Management School, Economics Division, UK, christopher.boyce@ stir.ac.uk

${ }^{2}$ University of Warsaw, Faculty of Economic Sciences, Dluga 44/50, 00-241 Warsaw, Poland, mc@uw.edu.pl

${ }^{3}$ University of Glasgow, Institute of Biodiversity, Animal Health and Comparative Medicine, Scotland, nicholas.hanley@glasgow.ac.uk
} 


\section{Highlights:}

- We set out a number of theoretical predictions for the effects of personality on individual economic choices

- We use a hybrid model to incorporate personality research into random utility framework

- Agreeableness, openness, and conscientiousness are found to influence preferences for environmental public goods as predicted

- Our results are consistent across three independent stated preference studies, and point to a wider role for personality measures in economic analysis.

\section{Acknowledgements:}

The data used in this study was collected within the project "Good environmental status through regional coordination and capacity building" (GES-REG) funded by the Central Baltic INTERREG IV A Programme 2007-2013 and the Environmental Investment Center of Estonia. MC gratefully acknowledges the support of the National Science Centre of Poland (project 2015/19/D/HS4/01972). We thank two referees and the editor for helpful comments on an earlier version. 


\title{
Personality and Economic Choices
}

\begin{abstract}
:
There is substantial variation in individual preferences for public goods, yet much of that variation remains poorly understood. However, simple measures of personality can help to explain economic values and choices in a systematic way. In this paper, we examine the effects of personality on individual economic choices over public environmental goods. Based on three datasets from three separate stated preference studies, we use a hybrid choice econometric framework to examine the effects of personality on preferences for the status quo, changes in environmental quality, and costs of investing in environmental improvements. We find effects that are consistent across all datasets. Personality, a stable feature of an individual's character that is simple to measure, enriches explanations of why the demand for environmental goods varies across people, provides an indication of how different people are likely to react to the introduction of environmental policies, and explains substantial differences in Willingness to Pay.
\end{abstract}

Keywords: personality, preference heterogeneity, hybrid choice models, stated preferences, choice models.

JEL codes: C35, D03, D12, D61, Q25, Q51

Revision for JEEM, June $29^{\text {th }}$ 


\section{Highlights:}

- We set out a number of theoretical predictions for the effects of personality on individual economic choices

- We use a hybrid model to incorporate personality research into random utility framework

- Agreeableness, openness, and conscientiousness are found to influence preferences for environmental public goods as predicted

- Our results are consistent across three independent stated preference studies, and point to a wider role for personality measures in economic analysis. 


\section{Introduction}

In a recent paper, Boyce, Wood and Ferguson (2016b) make the following comment:

"It is clear that the use of cognitive psychology (an area of psychology concerned with how people process information in general), has helped improve the predictive power of economic models, creating the hugely influential field of behavioural economics. However, although behavioural economics has helped us understand how people react on average, there is often substantial variation in individual reactions. The use of personality psychology (an area of psychology focusing on individual differences in reaction) has the potential to instigate a second wave of behavioural economics to predict individual-specific reactions to economic circumstances."

We show, using insights from psychology, that personality can be used to produce testable hypotheses on how economic choices and values vary between individuals. As noted by Grebitus, Lusk and Nayga (2013), “... personality might serve an important role in consistently predicting outcomes and explaining variation in economically-relevant behaviours" (page 11: emphasis added). Personality, we argue, can be considered in a similar manner to "standard" socio-economic variables, such as income, which are often used by micro-economists to explain heterogeneity in preferences for a particular class of goods, and to predict choices. Moreover, psychological theory and evidence can be exploited to produce testable, stable, and generalizable relationships between personality traits and economic choice, in much the same way as income can be used to explain demand heterogeneity in a predictable manner. Personality traits are simple to measure in household or individual surveys, using for instance a ten-item set of standard questions. We therefore argue that personality should not be consigned to the unobservables of a demand or indirect utility function, but should instead be treated as a measurable co-determinant of demand, alongside factors such as income, educational status, or age.

In this paper, we examine the effects of personality on individual economic choices over public environmental goods using a stated preference approach. We examine the potential for personality traits to explain preference heterogeneity within an environmental policy context. Based on three data sets from three separate, independent choice modelling studies, we examine 
the effects of personality on preferences for a change in the status quo, for changes in environmental quality, and over the costs of investing in environmental improvement. We show that incorporating personality research into economic models can provide valuable behavioural insights, since it allows a previously underexplored class of influences on preference heterogeneity to be modelled, thus enriching explanations of why the demand for environmental goods varies across people.

\section{Why personality?}

Personality is typically defined as patterns of thought, feelings and behaviour that persist from one decision situation to another (Wood and Boyce, 2014). Personality research in psychology and behavioural science spans several decades (Winter and Barenbaum, 1999) and in part originated out of a desire to understand how individuals might be expected to react and respond in various situations (John, Robins and Pervin, 2008). This body of work gave rise to the influential Five Factor Model (McCrae and Costa, 2008), whereby each individual can be characterized by differences across five broad dimensions: Agreeableness, Conscientiousness, Extraversion, Neuroticism, and Openness to Experiences. It is this Five Factor Model that we use in the research reported here.

The importance of personality for a range of life outcomes is now well established (Ozer and Benet-Martínez, 2006; Borghans et al., 2008). Personality has been shown to help explain a number of important behaviours and outcomes, including wage bargaining (Nyhus and Pons, 2005; Mueller and Plug, 2006), occupational success (Judge and Ilies, 2002), unemployment duration (Uysal and Pohlmeier, 2011; Fletcher, 2013; Egan et al., forthcoming), and well-being reactions to socio-economic events such as unemployment (Boyce, Wood and Brown, 2010), retirement (Kesavayuth, Rosenman and Zikos, 2016), marriage (Boyce, Wood and Ferguson, 2016a), and disability (Boyce and Wood, 2011b). Economists have argued that personality research needs to be integrated both theoretically and empirically into economic research (Borghans et al., 2008; Rustichini et al., 2012). Boyce, Wood and Ferguson (2016b) make the case that personality could have important implications for the behavioural sciences in particular with regard to their finding that one personality trait - conscientiousness - is important in 
determining the extent to which people are loss averse, though an examination of the effects of income gains and losses on subjective well-being.

However, despite the general increased use of concepts from psychology to better understand economic behaviour (Thaler and Sunstein, 2009), most economists remain unfamiliar with personality research and with how personality might be measured. This, and a lack of validated personality measures in large household panel surveys typically used by economists, has acted as a barrier to incorporating personality measures into a wider economic framework. Personality, however, can be measured quite easily by administering individuals with a self-report questionnaire that is designed to elicit what kind of person they are in general, and how they view the world. For example, an individual might be asked to indicate the extent to which they are someone who generally has a "forgiving nature", or "tends to be lazy". Such scales are widely used in psychology and undergo extensive validation exercises to ensure the scales measure what they are claimed to measure and are relatively consistent across behavioural contexts (Wood and Boyce, forthcoming).

We argue below that personality is a useful approach to studying preference heterogeneity within the context of the valuation of environmental goods. As far as we know, our paper is the first to test out this approach within a stated preference setting in a systematic manner, using the most widely accepted measure of personality. This seems a natural and useful extension of earlier work in stated preferences which explored the determinants of WTP using what one might call "non-standard economic variables", such as attitudinal statements or beliefs. Our focus is on the interaction of personality traits with stated preferences and stated willingness to pay for changes in an environmental good funded by the taxpayer,

\section{Personality and stated preferences}

Economists have mainly used demographic variables such as income and education as a way to explain variations in stated preferences for environmental improvements across respondents (e.g., Barbier, Czajkowski and Hanley, 2017), but there is growing awareness that what one may term "psychological variables" may also be important. Previous work has examined, for example, the effect of variables such as attitudes to local cultural heritage and wildlife conservation, and varying motivations to protect natural areas on willingness to pay (e.g., Nunes, 
2002; Onofri and Nunes, 2014; Faccioli et al., 2018). Nunes and Schokkaert (2003) apply this approach to the analysis of warm glow values within contingent valuation. ${ }^{1}$ Generally this body of work concluded that such psychological factors could explain some of the variation in stated willingness to pay for environmental protection. However, the psychological variables in these earlier papers are limited to motivational factors and have only a narrow focus with regard to the topic of interest. They did not examine stated preferences using generalizable personality measurement variables (the Five Factor Model) that have been developed over decades by personality psychologists.

Very few papers have examined the effects of personality in a stated preference context. Farizo, Oglethorpe and Soliño (2016) use a 240-item panel of questions with respondents to a stated preference study on preferences for wind farm location in Spain. Factor analysis was employed to identify 4 personality indices which were then related to individuals' choices using latent class analysis. The authors found that some ranges of stated choice depended on the personality factors. However, the authors do not derive any testable hypotheses from the psychological literature on which aspects of the choice scenarios should be most sensitive to particular personality traits. Mariel and Meyerhoff (2016) measure one aspect of personality (impulsiveness: an aspect of neuroticism) and find that variations in this trait helps explain variations in preferences for hypothetical changes to rural landscapes in Germany, through the effect on the probability of choosing the status quo option. However, no other measures of personality are explored in their study. Grebitus, Lusk and Nayga (2013) compare the effects of personality on real compared to hypothetical choices in two settings (an auction and a choice experiment) for two private goods (apples and red wine). Using a 30-item personality scale, they find that personality has an effect on willingness to pay which is generally greater in a choice experiment setting than an auction setting for the same good; and that the effects of personality differ according to whether choices or bids are hypothetical or not. They conclude that personality traits "may well explain a significant portion of hypothetical bias". The Grebitus, Lusk and Nayga (2013) study is conducted over values for private rather than public goods, and

\footnotetext{
${ }^{1}$ We also note the use of similar motivational factors in the analysis of well-being (e.g., Schokkaert and Van Ootegem, 1990). 
in a lab rather than a field setting. In contrast, we use a field setting to explore the effects of personality on choices for a public good within a stated preference environment. Finally, Morey and Thiene (2017) look at the stated recreational choices of "serious" mountain bikers, in terms of trail characteristics. The authors measure personality traits along 3 axes - competitiveness, sensation-seeking, and extraversion. An individual's score on these three axes is used to probabilistically allocate that person to a number of different latent preference classes. They find that site characteristics and an individual's personality traits jointly determine their choice of recreational site for mountain biking. This paper is most relevant to our own in terms of its discussion of the econometric problem of including personality traits within a stated choice model, namely that responses to personality questions may be measured with error. In what follows, we address this problem by using a hybrid mixed logit model.

In our study we make use of the Ten Item Personality Inventory (TIPI) which was designed, developed, and validated by Gosling, Rentfrow and Swann (2003) to measure the personality traits of respondents in three stated preference studies. The TIPI, which is much less timeconsuming to implement than many other "Five Factor" scales, has been developed specifically to enable personality traits to be measured under severe time-constraints. Although it poses limits on finer and more detailed aspects of the individual's personality, the approach has been validated in numerous studies (see e.g., Chamorro-Premuzic, Bennett and Furnham, 2007; Heller, Komar and Lee, 2007; Westmaas, Moeller and Woicik, 2007). We asked participants carrying out three separate stated preference discrete choice experiments concerned with prospective changes in coastal and marine water quality conducted in Estonia (two studies) and Latvia to complete the TIPI after they had responded to a series of choice tasks. After positing testable hypotheses based on the psychological literature for how personality affects preferences for aspects of environmental policy, we then test whether this measure of personality explains how preferences for environmental change vary across participants in the manner predicted. The next section gives more details of the choice experiments within which the TIPI questions were implemented.

3. Design of the choice experiments 
Choice modelling is now a very widely-used technique in economics, marketing and transportation research to understand preferences and predict demand for a very wide range of goods, services and policies (Hanley and Barbier, 2009; Hanley and Czajkowski, 2017). The approach derives its theoretical support from random utility theory and the characteristics theory of value. We designed and implemented three separate choice experiments in Latvia and Estonia. All three focused on different aspects of the marine and coastal environment. The studies were designed according to the state-of-the-art recommendations to mitigate hypothetical bias. Respondents were informed about outcome consequentiality and each scenario used a nonvoluntary payment mechanism (Carson and Groves, 2007; Johnston et al., 2017). Table 1 summarises the nature of these choice experiments, and Figure 1 shows an example choice card. In each choice task, respondents were asked to make choices from three options described using a number of environmental attributes and the cost of providing public goods at these levels. One choice option was always a zero-additional-cost opt-out, which was associated with no environmental improvement over a baseline. Personality questions were asked after the choice tasks were completed, along with a standard set of demographic questions. In all cases, we used a Bayesian D-efficient experimental design to construct the choice scenarios based on priors obtained from pilot study data (Scarpa and Rose, 2008). Where internet sampling was undertaken, samples representative of the national population were recruited from on-line consumer panels maintained by market research companies.

\section{Latvia}

This study focused on changes to marine and coastal ecological quality off the coast of Latvia. The environmental attributes used to form the choice sets were losses in native biodiversity (described as the areas over which this reduction would take place); water quality in summer in swimming areas (which is adversely affected by nutrient pollution and algal blooms); and invasive, harmful species (described in terms of the frequency of their establishment). The price attribute was increasing national taxes. The survey was undertaken in 2013, and a full account can be found in Pakalniete et al. (2017). The sample size was 1,247 people, and the data was collected by a mixture of internet panel-based questionnaires and in-house interviews with random samples of the general public. We did not rely entirely on internet sampling in Latvia, as internet access is quite low (less than 60\%) for people in the over 55 age group. 


\section{Estonia study 1}

This study was concerned with changes to pollution and biodiversity in the Baltic Sea off the coast of Estonia. The environmental attributes used to construct the choice sets were oil spills (their frequency, and the probability that a spill would reach the shoreline, which could be altered by investing in oil spill clean-up ships and equipment); water quality impacting on recreation (pollution originates from nutrient inputs such as fertiliser run-off and domestic sewage); and the arrival rate of invasive, non-native species. The cost attribute was again a rise in national income tax. Some 550 responses were collected using an on-line survey in 2013. Full details are provided in Tuhkanen et al. (2016).

\section{Estonia study 2}

This study was concerned with public preferences over the management of marine areas within Estonian national waters. The three management options were considered in two locations, namely (i) construction of a conventional off-shore windfarm; (ii) creation of an "environmentally-friendly" windfarm on the same site; and (iii) designating the site as a marine protected area. The cost attribute was an increase in national income taxes. The data was collected using a web-based survey in 2013, with 800 members of the general public. Full details can be found in Karlõševa et al. (2016).

In summary, we investigate the effects of personality on stated choices in three separate studies which share a number of characteristics: all are concerned with changes in the quality of the marine or coastal environment; all are examples of changes in public goods funded by the taxpayer. 
Table 1: summary of choice experiment design in the three data sets. For full information on how these attributes and choice options were described to respondents, please see original source papers

\begin{tabular}{|c|c|c|c|c|c|}
\hline & Attribute 1 & Attribute 2 & Attribute 3 & Attribute 4 & Attribute 5 \\
\hline $\begin{array}{l}\text { Latvia } \\
\text { (source: } \\
\text { Pakalniete } e t \\
\underline{\text { al. }(2017) \text { ) }}\end{array}$ & $\begin{array}{l}\text { Areas } \\
\text { experiencing } \\
\text { losses of native } \\
\text { species (over } \\
\text { large areas; } \\
\text { over small } \\
\text { areas; no- } \\
\text { where) }\end{array}$ & $\begin{array}{l}\text { Summer water } \\
\text { quality for } \\
\text { swimming } \\
\text { (bad, moderate, } \\
\text { good) }\end{array}$ & $\begin{array}{l}\text { New alien } \\
\text { (invasive) } \\
\text { species } \\
\text { establishing } \\
\text { populations } \\
\text { (often; rarely; } \\
\text { almost never) }\end{array}$ & & $\begin{array}{l}\text { Cost to } \\
\text { individuals: } \\
\text { rise in taxes. }\end{array}$ \\
\hline 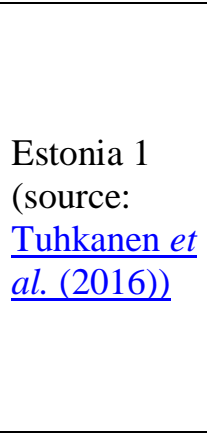 & $\begin{array}{l}\text { Oil spills at } \\
\text { sea: frequency } \\
\text { (rarely, } \\
\text { sometimes, } \\
\text { often, very } \\
\text { often) }\end{array}$ & $\begin{array}{l}\text { Oil spills at sea: } \\
\text { chance of the } \\
\text { oil reaching the } \\
\text { shoreline }(25 \% \text {, } \\
50 \%, 75 \% \text {, } \\
99 \%)\end{array}$ & $\begin{array}{l}\text { Invasive } \\
\text { Species } \\
\text { (one new } \\
\text { species every } \\
50 \text { years; every } \\
15-20 \text { years; } \\
\text { every year) }\end{array}$ & $\begin{array}{l}\text { Water quality } \\
\text { for recreation, } \\
\text { in terms of } \\
\text { clarity of sea } \\
\text { and algae } \\
\text { washed up on } \\
\text { beaches } \\
\text { (good, } \\
\text { moderate, } \\
\text { poor) }\end{array}$ & $\begin{array}{l}\text { Cost to } \\
\text { individuals: } \\
\text { rise in taxes. }\end{array}$ \\
\hline 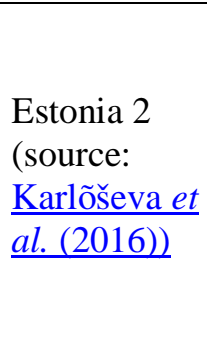 & $\begin{array}{l}\text { Location of } \\
\text { development: } \\
\text { at Apollo } \\
\text { Shoals; } \\
\text { at Western } \\
\text { Shoals. }\end{array}$ & $\begin{array}{l}\text { Type of } \\
\text { development: } \\
\text { None; new } \\
\text { wind farm; new } \\
\text { eco wind farm; } \\
\text { marine } \\
\text { protected area; } \\
\text { none }\end{array}$ & & & $\begin{array}{l}\text { Cost to } \\
\text { individuals: } \\
\text { rise in taxes. }\end{array}$ \\
\hline
\end{tabular}


Figure 1. Examples of the choice tasks used

1A. the Latvian choice experiment

\begin{tabular}{|l|c|c|c|}
\hline & Program A & Program B & $\begin{array}{c}\text { No additional } \\
\text { actions }\end{array}$ \\
\hline Reduced number of native species & No such areas & (on) Small areas & (on) Large areas \\
\hline $\begin{array}{l}\text { Water quality for recreation in coastal } \\
\text { areas }\end{array}$ & Bad & Good & Bad \\
\hline New harmful alien species establishing & Rarely & $\begin{array}{c}\text { In exceptional } \\
\text { cases }\end{array}$ & Often \\
\hline Your yearly payment & 5 LVL & 2 LVL & 0 LVL \\
\hline Your choice: & O & O & O \\
\hline
\end{tabular}

(Note: Each respondent received 12 such cards. Translation from original in Latvian and Russian)

1B: Estonia 1 study

\begin{tabular}{|l|l|c|c|c|}
\hline \multicolumn{2}{|l|}{ Problem } & Alternative A & Alternative B & $\begin{array}{c}\text { No additional } \\
\text { actions }\end{array}$ \\
\hline $\begin{array}{l}\text { Large-scale } \\
\text { oil pollution }\end{array}$ & $\begin{array}{l}\text { Cases of Large-scale } \\
\text { pollution of marine } \\
\text { waters }\end{array}$ & rarely & often & very often \\
\cline { 2 - 5 } & $\begin{array}{l}\text { Probability that pollution } \\
\text { reaches the shore }\end{array}$ & low & very high & very high \\
\hline Water quality for recreation & poor & moderate & poor \\
\hline $\begin{array}{l}\text { Introduction of new non-indigenous } \\
\text { species }\end{array}$ & often & $\begin{array}{c}\text { in exceptional } \\
\text { cases }\end{array}$ & often \\
\hline Annual cost to your household (EUR) & 10 & 20 & 0 \\
\hline $\begin{array}{l}\text { Alternative A } \\
\text { Alternative B } \\
\text { No additional actions }\end{array}$ & \multicolumn{2}{|l}{} \\
\hline
\end{tabular}

(Note: Each respondent received 12 such cards. Translation from original in Estonian and Russian) 


\begin{tabular}{|l|c|c|c|}
\hline & Status Quo & Alternative A & Alternative B \\
\hline Apollo shoal & No change & ECO-Windfarm & $\begin{array}{c}\text { Marine } \\
\text { Protected Area }\end{array}$ \\
\hline Western shoals & No change & Wind Farm & No change \\
\hline Cost to your household (EUR per year) & 0 & 10 & 5 \\
\hline YOUR CHOICE & $\square$ & $\square$ & $\square$ \\
\hline
\end{tabular}

(Note: Each respondent received 12 such cards. Translation from original in Estonian and Russian)

\section{Model formulation: testing the anticipated effects of personality on stated preferences.}

If personality is to be a useful aspect of individuals in terms of understanding their preferences, then we need to uncover stable, testable relationships between personality and the choice structure of stated preference studies. Below, we summarise what general, testable relationships can be deduced from the existing literature. How personality is measured will also help determine the best choice of modelling strategy to test for such relationships.

All three choice experiments described above were designed to address important environmental problems in the marine and coastal waters of Estonia and Latvia. In each choice experiment, there are two common components upon which personality might be predicted to have a systematic influence: the availability of a status quo baseline option, which involves no additional payment by an individual, resulting in no improvements in coastal and marine environmental quality; and the cost to the individual of choosing any non-status quo option. Across all three data sets we can thus examine the effects of an individual's personality on their tendency to prefer maintaining the status quo, i.e. to generally prefer no change in environmental quality, and second, their tendency to prefer choices with the lowest private cost.

In addition, we can investigate the effects of personality on preferences for specific environmental attributes. To explore whether personality is linked to pro-environmental attitudes 12 
we use just one data set (Latvia). This makes our examination more concise since one cannot compare non-price attributes across the three choice experiments, as the environmental attributes differ. Preference interaction results for the other two studies are available in Appendix 2.

We now summarise what effects could be expected to emerge from incorporating personality interactions into the choice experiment analysis, based on the personality literature in psychology and behavioural science. These predictions on the effects of personality traits on strength of preference towards the status quo, cost and specific environmental attributes are summarised in Table 2.

\subsection{Expectations for preferences toward the status quo}

In many decision tasks there is a well-known tendency for individuals to disproportionately prefer to maintain the status quo (Samuelson and Zeckhauser, 1988) and several personality traits have been associated with this tendency. Status quo bias has often been explained by a general preference to avoid losses, such that individuals tend to prefer what they have relative to what they could obtain (Kahneman, Knetsch and Thaler, 1991). Some individuals may be more likely to have an adverse reaction to loss than others and this can depend on personality. For example, people that are high in neuroticism (prone to anxiety, depression, and emotional instability), have been found to be more sensitive to a loss than those low in neuroticism (Hartley and Phelps, 2012). Neurotic individuals may therefore have a stronger desire to prefer to maintain the status quo than those that are less neurotic. Conscientious individuals are generally cautious, orderly, and dutiful (Costa, McCrae and Dye, 1991), and at the extreme are characterised as somewhat rigid in thought (Nettle, 2006). Thus it seems likely that conscientious individuals will also have a stronger preference for maintaining the status quo. It has been demonstrated that under certain conditions the classic loss aversion effect is stronger among conscientious individuals (Boyce, Wood and Ferguson, 2016b). Contrastingly, individuals that score high on openness-to-experiences place higher importance on adventure and action (McCrae and Sutin, 2009) and are more likely to be curious (Nettle, 2006) and seek creative solutions to problems (George and Zhou, 2001). Thus, individuals who score high on opennessto-experiences are less likely to have a preference for the status quo (Lee et al., 2010). 
To summarise we hypothesise that individuals who score highly on neuroticism or on conscientiousness will have a tendency to opt for the status quo. Those high on openness are predicted to be less likely to want to maintain the status quo. There is no strong a priori reason to expect people who score high with regard to the other personality traits (extraversion and agreeableness) to prefer the status quo option. However, such personality traits might still have a significant effect on preferences towards the status quo option owing to people's preferences for the environmental attributes specific to each of the studies, and thus with the consequences of voting for the status quo.

\subsection{Expectations for sensitivity to cost}

Individuals high in openness tend to value intellectual pursuits over profit seeking (Renner, 2003) and it has been shown that income changes have lower effects on well-being for those that have high levels of openness (Boyce and Wood, 2011a). We therefore expect that those who are high in openness will be less likely to avoid choices that have a high personal cost. Those that are conscientious, on the other hand, tend to place a higher value on wealth accumulation (Ameriks, Caplin and Leahy, 2003; Ameriks et al., 2007) and also tend to value economic over non-economic goals (Roberts and Robins, 2000). Thus, they are likely to be less willing to choose options with high personal cost. In line with this it has been demonstrated that an income loss has a larger impact on well-being among the highly conscientious than those less conscientious (Boyce, Wood and Ferguson, 2016b).

There is no strong a priori reason to expect the other personality traits, extraversion, agreeableness, and neuroticism, to be sensitive to cost. As with the status quo option, such personality traits might still interact significantly with the costs option owing to preferences for the environmental attributes specific to each of the studies. However, it is not possible to predict the sign of this effect from the psychological literature.

\section{$\underline{4.3 \text { Expectations for specific environmental attributes }}$}

Researchers have begun to explore the extent to which personality predicts the strength of environmental concern in an individual. Several traits have been implicated, most notably agreeableness (the tendency for an individual to be trusting, altruistic and compliant) ( $\underline{\text { Costa, }}$ 
McCrae and Dye, 1991) and openness are related to having a higher concern for the environment (Hirsh, 2010; Markowitz et al., 2012; Hirsh, 2014). Thus, we hypothesize that individuals who indicate they have high levels of agreeableness and openness will more likely make choices that benefit the environment, and thus show stronger preferences for the environmental improvements within each choice experiment than others. Pro-environment behaviours, such as whether an individual engages with recycling schemes, have been shown to depend on conscientiousness, agreeableness and openness (Swami et al., 2011; Milfont and Sibley, 2012). Thus, conscientious individuals may also be more likely to make stated choices that relate to environmental improvements. These expected findings of personality trait on stated preferences are shown in Table 2.

Table 2: summary of predictions from psychology literature on expected effects of personality traits on preferences towards status quo option, cost and environmental attributes

\begin{tabular}{|c|c|c|c|}
\hline Personality trait & $\begin{array}{c}\text { Expected effect on status } \\
\text { quo (SQ) }\end{array}$ & $\begin{array}{l}\text { Expected effect on } \\
\text { preferences towards } \\
\text { cost }\end{array}$ & $\begin{array}{l}\text { Expected effects on } \\
\text { preferences for } \\
\text { environmental gains }\end{array}$ \\
\hline Neuroticism & $\begin{array}{l}\text { Individuals high in } \\
\text { neuroticism likely to have } \\
\text { stronger preferences for } \\
\text { maintaining SQ }\end{array}$ & No prediction & No prediction \\
\hline Conscientiousness & $\begin{array}{l}\text { More conscientious } \\
\text { individuals likely to have } \\
\text { stronger preferences for } \\
\text { maintaining SQ }\end{array}$ & $\begin{array}{l}\text { More likely to avoid } \\
\text { costly options, so } \\
\text { expect higher } \\
\text { sensitivity to price }\end{array}$ & $\begin{array}{l}\text { Stronger preferences } \\
\text { for environmental } \\
\text { improvements }\end{array}$ \\
\hline Openness & $\begin{array}{l}\text { Individuals scoring high } \\
\text { on openness to experience } \\
\text { likely to have weaker } \\
\text { preferences for SQ }\end{array}$ & $\begin{array}{l}\text { Less likely to avoid } \\
\text { costly options, so } \\
\text { expect lower price } \\
\text { sensitivity }\end{array}$ & $\begin{array}{l}\text { Stronger preferences } \\
\text { for environmental } \\
\text { improvements }\end{array}$ \\
\hline Agreeableness & No prediction & No prediction & $\begin{array}{l}\text { Stronger preferences } \\
\text { for environmental } \\
\text { improvements }\end{array}$ \\
\hline Extraversion & No prediction & No prediction & No prediction \\
\hline
\end{tabular}

\section{Modelling approach}


To analyse the stated choice data in the context of personality trait information we use the hybrid mixed logit model (HMXL), a structural econometric model that allows us to link ordinal responses to the personality questions to respondents' economic choices (e.g., Ben-Akiva et al., 2002; Hess and Beharry-Borg, 2012; Czajkowski, Hanley and Nyborg, 2017; Czajkowski et al. 2017). At the heart of the empirical modelling lies the assumption that each respondent's personality can be described using five personality traits: Extraversion, Agreeableness, Conscientiousness, Neuroticism and Openness-to-Experiences. These traits are not directly observed - they are being modelled as latent (unobserved) variables. However, they can be indirectly measured because they drive responses to questions as to how individuals see themselves in personality terms. Moreover, use of a hybrid choice model is one way of responding to a worry over measurement bias (Budziński and Czajkowski, 2017).

In our survey we included ten questions designed specifically to measure the five personality traits and extensively used in psychology (Gosling, Rentfrow and Swann, 2003). As detailed in Section 4, people who score high or low on particular personality traits can be expected to differ from the remainder of the population with respect to their economic preferences. To this end, the latent variables of our model also enter respondents' utility functions - they are interacted with all choice attributes to investigate differences in the economic preferences of people according to their personality traits. Figure 2 presents the general structure of the model, while Appendix 1 provides the technical details.

The econometric framework we use has several advantages. First of all, the personality question responses were collected using 7-point Likert scales (see Annex). It is common in the psychometric literature to impose an absolute interpretation on these Likert-scale responses. Instead, our structural model uses an ordered probit to model these answers, and hence recovers the ordinal nature of the response scale without imposing other restrictions. This way we do not mis-interpret the responses and avoid potential bias resulting from modelling responses using, for example, linear regression (Greene, 2017). ${ }^{2}$ Secondly, each of the personality traits was

\footnotetext{
${ }^{2}$ Instead, many studies assume linear relationship between responses (i.e. assume equal distance between response scales), for example interpreting 'I disagree strongly' as 1, 'I disagree moderately' as 2 and so on. This is a very strong assumption to impose, since the differences between response categories are much subtler and while there 16
} 
measured using two attitudinal questions (so 5 traits imply 10 questions). It is common practice to assume that each of the attitudinal questions has equal weight, for example by simply adding up (following possible reverse coding as necessary) responses to each of the two questions corresponding to the same trait (e.g., Gosling, Rentfrow and Swann, 2003). Our framework, however, accounts for the possibility that one of the questions is more efficient in measuring a particular personality trait than the other - each latent variable enters each of the two corresponding attitudinal questions with a separate coefficient, hence allowing for an independent relationship. Finally, all components of our structural model are estimated jointly the model is estimated using full information log-likelihood function. Many other studies have employed a two-step approach (in somewhat different contexts), in which for example individual factor scores are derived first and then interacted with utility function parameters (e.g., Salomon and Ben-Akiva, 1983; Boxall and Adamowicz, 2002; Nunes and Schokkaert, 2003; Milon and

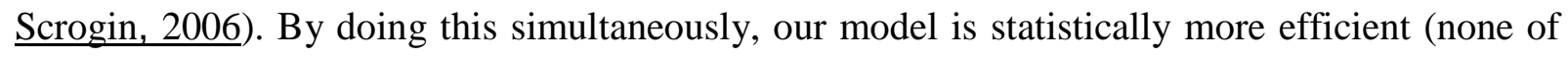
these papers consider the effects of personality traits on stated preferences).

could be very little difference between 'I disagree strongly' and 'I disagree moderately', there could be much more difference between 'Neither agree nor disagree' and 'Agree a little'. Using the ordered probit model does not impose this assumption - it uses ordinal scale to interpret responses and flexibly sets the thresholds between neighboring responses. 
Figure 2. Structure of the HMXL model

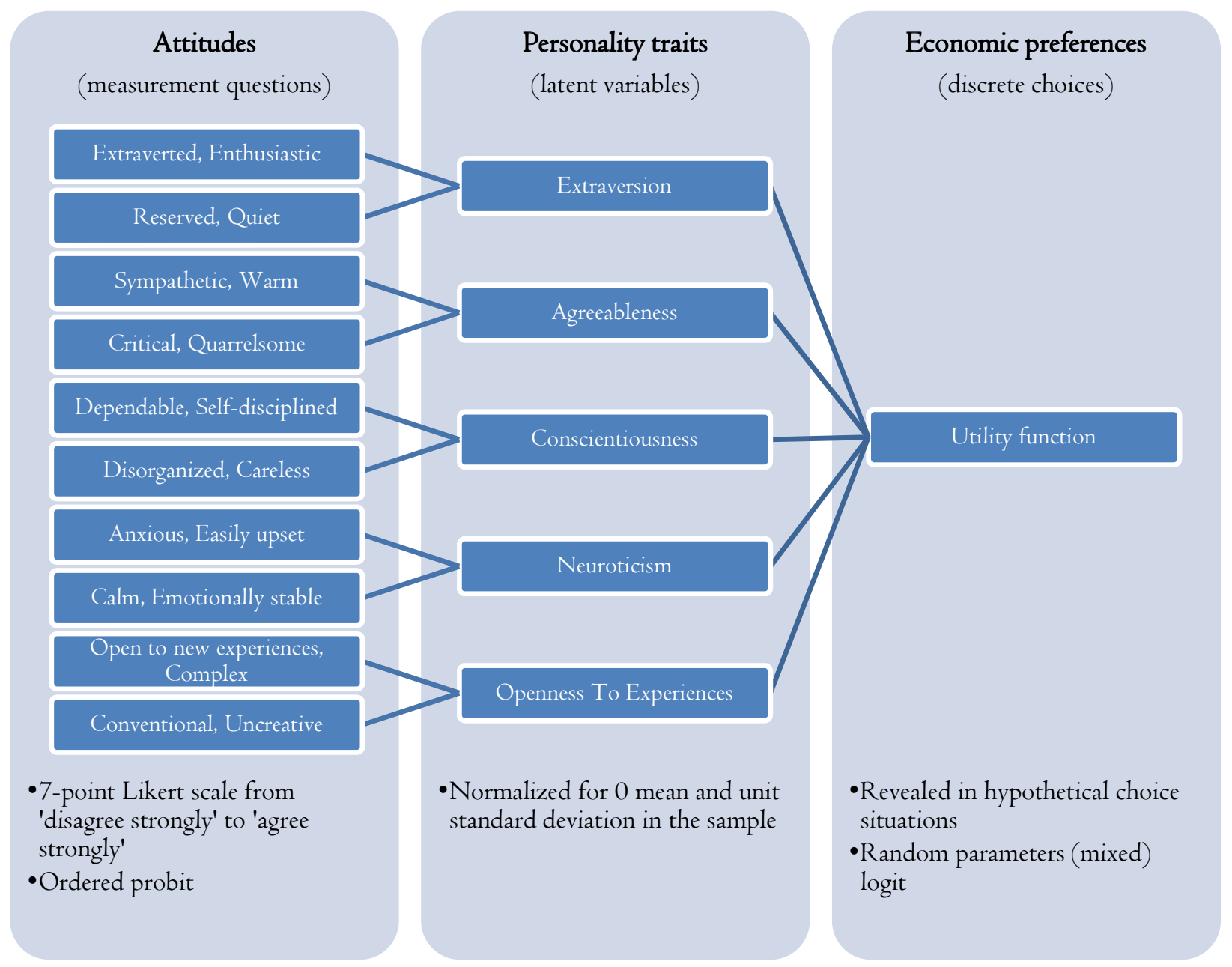




\section{6. $\underline{\text { Results }}$}

The data collected from the three case studies described in section 3 was analysed using the HMXL model outlined in section 5. The detailed estimation results and their interpretation are provided in Appendix 2. ${ }^{3}$ In what follows, we focus on verifying the effect of personality traits on preferences towards the status quo and cost sensitivity across all three datasets, based on the predicted effects set out in Table 2. We then use the Latvian dataset to investigate the effects of personality traits for WTP for all choice attributes.

\subsection{Preferences towards the Status Quo and cost attributes}

The alternative specific constant associated with the status quo represents respondents' preferences towards any change relative to the baseline situation presented in each choice experiment. The cost coefficient shows how peoples' choices respond to variations in the cost to the respondent of each choice alternative and corresponds to their marginal utility of income. Overall, we observe that personality does correlate with individual's preferences for the status quo and for the cost attribute. These findings are summarized in Table 3, and can be compared to the anticipated effects shown in Table 2. Although the coefficients presented in Table 3 do not have direct interpretations in absolute terms (their absolute levels should not be compared between studies), their signs and relative values indicate the correlation with specific personality traits and the strength of their relative influence. Coefficients whose sign (though they are not necessarily statistically significant) are in line with our expectations as set out in Table 2 are marked green, whilst coefficients that do not are marked red.

\footnotetext{
${ }^{3}$ The datasets, additional results and estimation codes are available from the authors upon request.
} 
Table 3. Personality traits and economic preferences for status quo and cost - summary of findings

\begin{tabular}{lcccccc}
\hline \multicolumn{1}{c}{ Observed effect for: } & \multicolumn{2}{c}{ The alternative specific constant } & \multicolumn{3}{c}{ Cost coefficient } \\
& Latvia & Estonia 1 & Estonia 2 & Latvia & Estonia 1 & Estonia 2 \\
Extraversion & -0.23 & $-0.62 *$ & $0.39 * *$ & $2.45 * * *$ & $0.31 * *$ & $-2.52 * * *$ \\
Agreeableness & $-0.57 * * *$ & 0.42 & $2.88^{* * *}$ & $1.15 * * *$ & $0.57 * * *$ & $-4.44 * * *$ \\
Conscientiousness & 0.12 & 0.06 & $-0.36 *$ & $0.25 * * *$ & $0.36 * *$ & $1.40 * * *$ \\
Neuroticism & $0.58 * * *$ & 0.20 & $0.96 * * *$ & 0.01 & 0.04 & $-2.23 * * *$ \\
Openness To Experiences & $-1.72 * * *$ & $-0.67 * *$ & 0.00 & $-2.05 * * *$ & -0.22 & $-3.28 * * *$ \\
\hline
\end{tabular}

Notes: $* * *, * *$ and $*$ indicate significance at the level of $1 \%, 5 \%$, and $10 \%$, respectively.

Consistent with our expectations, in at least 2 out of the 3 datasets we find that respondents who are more open to experiences are also significantly less likely to prefer the status quo, and more likely to have lower a marginal utility of income. Similarly, respondents who are more neurotic are more likely to prefer the status quo in all of our datasets (in 2 instances being statistically significant). Conscientiousness does not seem to positively correlate with stronger preferences for the status quo, and in fact, in the case of one dataset the correlation is significantly negative: this runs counter to a priori expectations. ${ }^{4}$ On the other hand, more conscientious respondents are consistently 'more careful with money', i.e. their choices reveal significantly higher sensitivity to cost increases in all three datasets.

In addition, we observe some effects of personality for which we do not have clear expectations. Extraversion is negatively related with the preferences for status quo in Estonia 1 study, and negatively in Estonia 2 study. In the case of 2 datasets, the marginal utility of income for those scoring high on extraversion is greater (and hence their WTP lower), while in the case of Estonia 2 dataset - it is actually lower (implying higher WTPs). The effects of agreeableness for the observed preferences for status quo and the cost parameter are statistically significant, but mixed - the effect is different for different datasets.

\footnotetext{
${ }^{4}$ Because the status quo alternative in the case of this study represented no development (neither erecting wind park nor establishing marine protected area) it is possible that it was perceived differently than in the other two studies, where the status quo alternative was a clear 'no improvement' option.
} 
Overall, we conclude that our expectations regarding the influence on estimated preferences of openness to experiences and neuroticism are confirmed. In the case of conscientiousness, we find consistent (and expected) effects for cost sensitivity, but not for the preferences towards keeping the status quo. We also observe other effects of personality traits - for these we do not have a priori expectations based on findings in the psychological literature. However, these effects likely depend on individual perceptions of specific environmental attributes used in the three experiments.

\subsection{Willingness to pay for environmental improvements}

Next, we focus on one of our cases studies, Latvia, to explore the role of personality in predicting preferences and Willingness To Pay (WTP) for changes to specific environmental attributes through which the policy options are described to respondents. Note that the effect for WTP is not straightforward - for example, if we expect that more conscientious respondents care more about some environmental attributes, but are also more sensitive to the cost of providing these environmental goods, then their WTP could be either higher or lower than average, depending on which of the effects prevails (since WTP is defined as the ratio of the cost parameter to the relevant preference parameter).

The results of the model in which personality traits are interacted with all choice attributes are presented in Appendix 3. To facilitate interpretation, the model is estimated in WTP-space (Train and Weeks, 2005), so that the attribute coefficients in the choice model can readily be interpreted as respondents' marginal WTP for specific attributes. Table 4 presents the simulated mean WTP for each of the attributes. The 'baseline' WTP represents all respondents in the sample, i.e. WTP for someone with mean scores for each personality trait. Next, we illustrate the effect of personality by simulating WTP of someone who would be a unit standard deviation above or below the population mean for each of the personality traits. 
Table 4. Marginal WTP (EUR) of respondents in the Latvian choice experiment with different intensity of personality traits (95\% confidence interval provided in parentheses)

\begin{tabular}{|c|c|c|c|c|c|}
\hline Personality & & Status quo & $\begin{array}{c}\text { Reduced } \\
\text { number of } \\
\text { native species }\end{array}$ & $\begin{array}{l}\text { Water quality } \\
\text { for recreation }\end{array}$ & $\begin{array}{l}\text { New harmful } \\
\text { alien species }\end{array}$ \\
\hline Baseline & population mean & $\begin{array}{c}11.93 * * * \\
(9.08 ; 15.02)\end{array}$ & $\begin{array}{c}-0.02 * * * \\
(-0.30 ; 0.26)\end{array}$ & $\begin{array}{c}4.52 * * * \\
(3.96 ; 5.08)\end{array}$ & $\begin{array}{c}0.66^{* * * *} \\
(0.40 ; 0.91)\end{array}$ \\
\hline Extraversion & 1 s.d. below mean & $\begin{array}{c}-8.41 * * * \\
(-11.71 ;-5.18) \\
32.32 * * * \\
(27.43 ; 37.46)\end{array}$ & $\begin{array}{c}-0.52 * * * \\
(-0.94 ;-0.09) \\
0.48 * * * \\
(0.21 ; 0.74)\end{array}$ & $\begin{array}{c}4.80 * * * \\
(4.06 ; 5.55) \\
4.24 * * * \\
(3.73 ; 4.74)\end{array}$ & $\begin{array}{c}1.21 * * * \\
(0.79 ; 1.63) \\
0.10 * * * \\
(-0.16 ; 0.36)\end{array}$ \\
\hline \multirow{2}{*}{ Agreeableness } & 1 s.d. below mean & $\begin{array}{c}12.74 * * * \\
(9.51 ; 16.18)\end{array}$ & $\begin{array}{c}0.84 * * * \\
(0.32 ; 1.36)\end{array}$ & $\begin{array}{c}9.18 * * * \\
(8.10 ; 10.24)\end{array}$ & $\begin{array}{c}0.92 * * * \\
(0.47 ; 1.37)\end{array}$ \\
\hline & 1 s.d. above mean & $\begin{array}{c}11.14 * * * \\
(8.23 ; 14.24)\end{array}$ & $\begin{array}{c}-0.88 * * * \\
(-1.21 ;-0.55)\end{array}$ & $\begin{array}{c}-0.14 * * * \\
(-0.64 ; 0.38)\end{array}$ & $\begin{array}{c}0.39 * * * \\
(0.06 ; 0.73)\end{array}$ \\
\hline \multirow{2}{*}{ Conscientiousness } & 1 s.d. below mean & $\begin{array}{c}11.36^{* * * *} \\
(8.44 ; 14.51)\end{array}$ & $\begin{array}{c}0.09 * * * \\
(-0.26 ; 0.44)\end{array}$ & $\begin{array}{c}3.88 * * * \\
(3.33 ; 4.44)\end{array}$ & $\begin{array}{c}0.47 * * * \\
(-0.01 ; 0.94)\end{array}$ \\
\hline & 1 s.d. above mean & $\begin{array}{c}12.51 * * * \\
(9.53 ; 15.65)\end{array}$ & $\begin{array}{c}-0.13 * * * \\
(-0.55 ; 0.30)\end{array}$ & $\begin{array}{c}5.15 * * * \\
(4.38 ; 5.91)\end{array}$ & $\begin{array}{c}0.84 * * * \\
(0.32 ; 1.37)\end{array}$ \\
\hline \multirow{2}{*}{ Neuroticism } & 1 s.d. below mean & $\begin{array}{c}13.63 * * * \\
(10.67 ; 16.82)\end{array}$ & $\begin{array}{c}0.07 * * * \\
(-0.26 ; 0.41)\end{array}$ & $\begin{array}{c}4.17 * * * \\
(3.62 ; 4.73)\end{array}$ & $\begin{array}{c}0.37 * * * \\
(0.05 ; 0.70)\end{array}$ \\
\hline & 1 s.d. above mean & $\begin{array}{c}10.25 * * * \\
(7.30 ; 13.34)\end{array}$ & $\begin{array}{c}-0.12 * * * \\
(-0.54 ; 0.30)\end{array}$ & $\begin{array}{c}4.87 * * * \\
(4.14 ; 5.57)\end{array}$ & $\begin{array}{c}0.94 * * * \\
(0.53 ; 1.35)\end{array}$ \\
\hline \multirow{2}{*}{$\begin{array}{l}\text { Openness To } \\
\text { Experiences }\end{array}$} & 1 s.d. below mean & $\begin{array}{c}17.22 * * * \\
(13.91 ; 20.78)\end{array}$ & $\begin{array}{c}-0.50 * * * \\
(-0.92 ;-0.08)\end{array}$ & $\begin{array}{c}2.25 * * * \\
(1.57 ; 2.93)\end{array}$ & $\begin{array}{c}0.28 * * * \\
(-0.02 ; 0.60)\end{array}$ \\
\hline & 1 s.d. above mean & $\begin{array}{c}6.66 * * * \\
(3.81 ; 9.59)\end{array}$ & $\begin{array}{c}0.45 * * * \\
(0.02 ; 0.89)\end{array}$ & $\begin{array}{c}6.79 * * * \\
(6.06 ; 7.51)\end{array}$ & $\begin{array}{c}1.03 * * * \\
(0.65 ; 1.39)\end{array}$ \\
\hline
\end{tabular}

$*, * *, * * *$ represent statistical significance of the difference at the $0.1,0.05,0.01$ level. In the case of the baseline we test if the values are significantly different than 0 . In the other cases, we test for a significant difference with respect to the baseline.

Overall, these results provide an indication of possible WTP changes associated with the differences in respondents' personality traits for the three environmental attributes used in the Latvian study. In the first row of the table, we show that the average of WTP for improvements in each attribute is significantly different from zero: people state that they are willing to pay higher taxes for each of these environmental improvements. In the remainder of the table, the effects of a change in each personality trait (by one standard deviation above and below the mean level this trait) on this baseline WTP value can be seen. Taking "agreeableness" as an example for personality trait and the "water quality for recreation" attribute, it can be seen that being one SD below the mean in terms of their agreeableness score implies a marginal WTP of 9.18 euro per person per year (WTP of a respondent with the mean level of agreeableness is equal to 4.52 euro). Being one standard deviation above the mean score for agreeableness implies a marginal WTP of -0.14 euro, so it actually becomes negative for respondents who score low on this 
personality trait. For openness to experiences, being one SD below the mean score for this personality trait implies a WTP of 2.25 euro relative to a baseline WTP of 4.52, whilst being one SD above the mean openness to experience score implies a WTP of 6.79 euro. These differences are large.

The simulation presented here shows that differences in personality traits can lead to significant changes in respondents' preferences and WTP. In this case, being one SD above or below the mean level of each personality trait leads to statistically significant differences in WTP relative to the baseline. Interestingly, high or low enough personality trait scores can even lead to reversing the sign of WTP, i.e. changing the attribute from a 'good' to 'bad'. Although a specific score for an individual on one of the personality traits may produce a low or negative WTP it is possible that this effect may be cancelled out or minimized through the individual also having a score on another personality trait. For example, an individual might have a neuroticism score one standard deviation below the mean that results in them less likely to be willing to maintain the status quo, but have a conscientious score one standard deviation above the mean which may make them simultaneously more willing to maintain the status quo giving them a WTP that does not deviate much from the average. Likewise, however, an individual may have a personality profile that results in cumulative negative influence on their WTP.

Overall, we find that personality provides an important means for explaining heterogeneity in preferences and WTP values. In addition to the results presented in Table 4, Figure 4 presents graphical illustration of how marginal WTP for each of the attributes change with individual respondents' personality traits (relative to the population mean). Large WTP changes and narrow confidence intervals correspond to observing relevant personality effects. 
Figure 4. Marginal WTP (EUR) of respondents with different intensity of personality traits

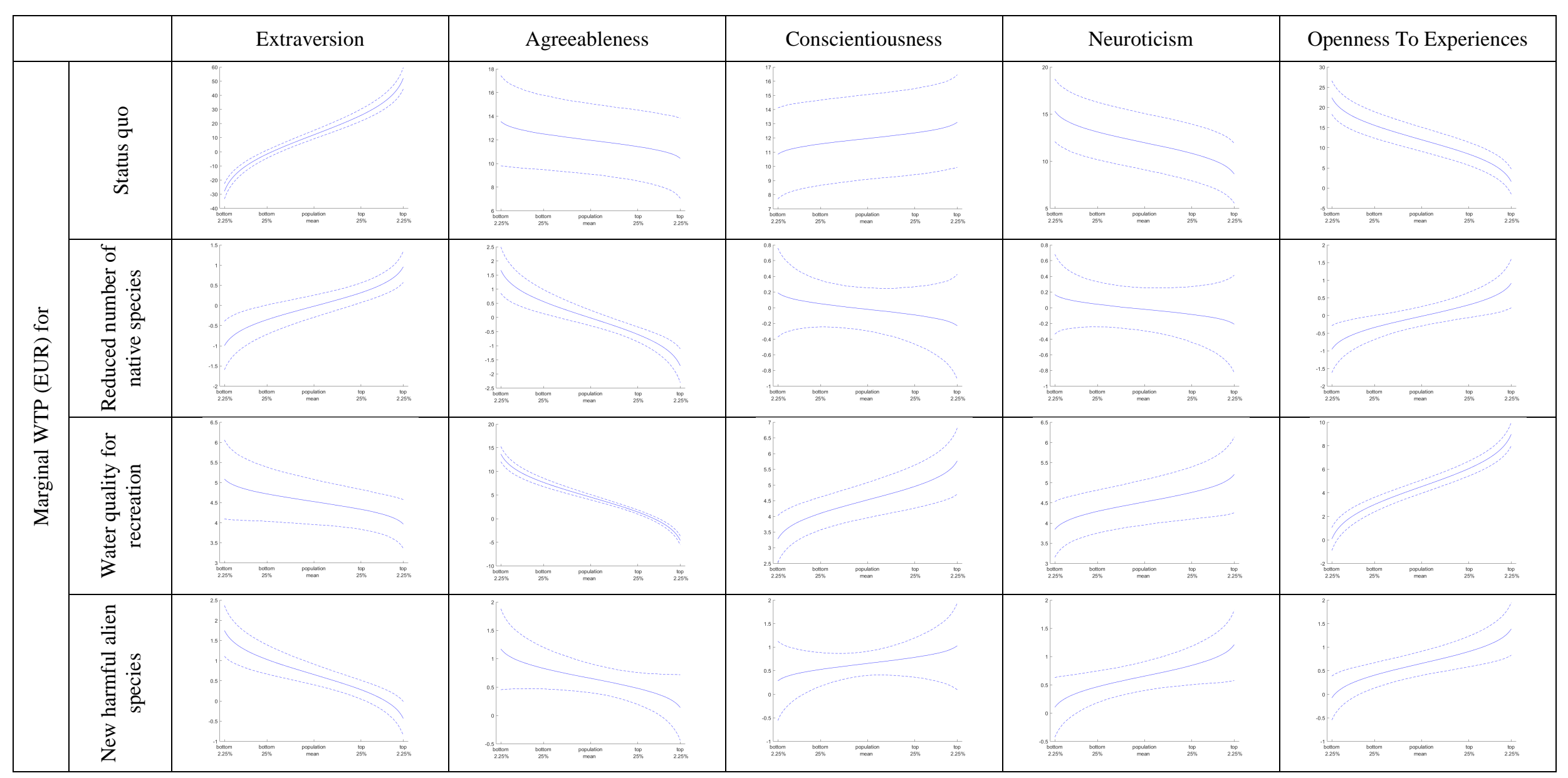




\section{Discussion and Conclusions}

Personality research has a long history in psychology (McCrae and Costa, 2008) yet the potential for personality to inform economic analysis has only just begun to be recognized (Borghans et al., 2008; Almlund et al., 2011; Rustichini et al., 2012). It has been suggested that personality research may even help instigate a second wave of behavioural economics by enabling researchers to better understand individual differences in economic behaviour (Boyce, Wood and Ferguson, 2016b).

But why should economists care about personality? We think the reasons are as follows. Developing better, more complete explanations for preference heterogeneity is important, since it better enables us to explain people's choices and values in a wide range of contexts. Personality is a stable feature of an individual's character; which psychologists have found to be a useful predictor of behaviour. Moreover, there are well-established and simple means of measuring people's personality, which can be implemented in the kinds of survey instruments routinely employed in environmental economics. Using insights from psychology, it is possible to set out a number of consistent, testable relationships between personality traits and (i) preferences for the status quo (ii) cost and (iii) environmental attributes.

Here we present the first systematic examination of the effects of personality on individual economic choices over public goods, using a stated preference approach. Using three independent datasets from separate stated preference studies, we show that personality helps explain preference heterogeneity and the heterogeneity of WTP within an environmental choice context. The effects of variation in personality on WTP are not trivial - for example, resulting in a 3-fold increase in WTP for being one standard deviation below versus above the mean personality score (e.g., "openness to experience" and WTP for improving quality of recreational waters in Table 4). So the effects are not only consistent, but sizeable as well. Moreover, we find evidence in three, entirely independent data sets to support such relationships between personality and preferences.

Even if hypothetical bias results in an inflation of WTP values, the relative changes in stated WTP produced by variations in personality trait are striking and meaningful. Most work to date on the extent and likelihood of hypothetical bias in stated preferences has focussed on the issues 
of outcome and payment consequentiality, and the format within which WTP values are elicited. Personality, as we have shown here, can be a good predictor of how respondents view the cost attribute within choice experiments. It seems feasible, therefore, that a study comparing real with hypothetical payments for a public good which also measured personality traits using the five factor model we employ might well find that, all else equal, personality explains both the likelihood and the extend of hypothetical market bias. Since personality determines people's attitudes to changes away from the status quo (as we have demonstrated), this also suggests that personality might co-determine hypothetical bias. However, we are not able to test this in any of the 3 data sets used here.

We demonstrate that personality plays an important role in predicting whether an individual has preferences to maintain the status quo and to avoid choices that improve environmental quality at a cost to the respondent. Given previous research in psychology, we predicted that individuals with lower levels of openness to experience, higher levels of neuroticism, or higher levels of conscientiousness would have a tendency to opt for the status quo. We also predicted that those with higher levels of conscientiousness or lower levels of openness would be more sensitive to cost. In the three independent data sets used here, we found openness predicted the extent to which maintaining the status quo was preferred (negative interaction effect in 2 of the 3 datasets, the other positive but insignificant) as well as the extent to which costs should be avoided (negative interaction effect in 2 of the 3 datasets, the other insignificant). We also found, as predicted, that neuroticism was linked to preferences for the status quo (negative interaction effect in 2 of the 3 datasets, the other insignificant). Conscientiousness was found to predict the extent to which choices with lower costs were preferred (positive interaction effect in all 3 datasets) as predicted. However, we found limited evidence that conscientious individuals were more likely to prefer the status quo (a negative interaction effect, as opposed to an expected positive interaction in 1 of the 3 datasets, the others being positive but insignificant).

One explanation for this limited effect of conscientiousness is that the tendency to want to maintain the status quo is dependent upon an individual's goal orientation (Chernev, 2004). Since conscientious individuals have a tendency to be highly motivated (Judge and Ilies, 2002) 
and goal focused (Barrick, Mount and Strauss, 1993), they may also particularly value the goal in question (e.g., a cleaner marine environment), and hence may actually be highly averse to the status quo, which in two of our data sets is clearly linked to a relatively poor level of environmental quality. An alternative explanation is that important aspects of conscientiousness may have opposing effects on preferences. We used a personality scale that had only ten items and such a scale is typically used when researchers have severe time constraints. Ten items is the absolute minimum number of items and gives a reliable indication of an individual's personality at a very broad level. However, personality psychologists prefer to use much larger scales ( $\underline{\text { Costa }}$ and McCrae, 2008), as each of the five broad traits can be broken down further into six subdomains or facets. Conscientiousness, for example, consists of competence, order, dutifulness, achievement striving, self-discipline, and deliberation. It is therefore conceivable that some aspects of conscientiousness, such as achievement striving and competence, may result in preferences for change away from the status quo, whilst others, such as order and self-discipline, may result in preferences for maintaining the status quo. Given we were unable to differentiate between more nuanced aspects of conscientiousness in our study, as well as any of the other broad traits, this may have limited our ability to detect more subtle effects. Now that we have shown personality as an important effect at the broad level we hope that future research will examine personality at a more detailed level.

Unexpectedly, we also found that other personality traits interacted across datasets with the status-quo and cost attributes. In particular, extroversion was linked to maintaining the status quo (negative interaction effect in all two of the datasets, and positive in the other) as well as the extent to which costs should be avoided (positive interaction effect in 2 of the 3 datasets, the other negative). There were also some effects from those scoring higher on the trait of agreeableness, but these were inconsistent across the datasets. These unexpected and inconsistent results are likely to have arisen owing to preferences for the environmental attributes specific to each of the studies. For example, extraverted or agreeable individuals may have preferred attributes that varied across the choice experiments but had differing personality-specific consequences (e.g., better water quality for sea swimming) that resulted in them being more likely to select a study-specific attribute rather than be in favour or against the status quo option per se. We did, however, predict that agreeable individuals, along with those that were more 
open or conscientious, would have stronger preferences for environmental improvements. We found that indeed WTP for environmental improvements was generally higher among those with higher levels of openness, agreeableness, and conscientiousness. We additionally found that extraversion played an important role in explaining individual differences in WTP.

One potential criticism of our work is that with a large number of potentially testable hypotheses we are susceptible to chance findings. However, we think it unlikely our results were the product of chance findings for several reasons. First, we set out the hypotheses to be tested and our predictions based on the current literature. Second, we used 3 different data sets and although we found some surprise effects, as addressed above, found consistency in the evidence across the datasets.

Overall, our results have interesting implications for stated preference modelling. Status-quo and cost variables are nearly always included in choice models, and since preferences for these vary by personality, our research demonstrates that personality has the potential to enrich these types of models. Although typical choice models may give some sense of an overall population-level preferences or valuation, such average effects may reflect an amalgamation of a huge diversity individuals. For example, whilst some individuals may have particularly high WTP, others may have low WTP, or even need to be compensated. Insights from the kind of research reported here would help a policy maker understand what motivates some people from not wanting a proposed environmental policy change to go ahead, in terms of their preferences towards the attributes of the environmental good, the fact of a change away from the status quo, and the cost of the project. It could also help policy managers fine-tune information provision to make it more salient to different respondents. A 'one size fits all' approach may result in discontent from some of the population and indeed some may believe that their views have not been considered at all. However, we believe it would be odd for policy-makers to fine-tune policy implementation to take account of variations in WTP according to personality in the affected population, even if they were able to do so. Neither do we see a role for personality measurements in improving benefit transfer protocols.

In conclusion, our research highlights the role of personality traits in explaining which individuals care more about the environment and have a higher demand for environmental public 
goods. Generalizable and testable relationships exist between personality traits and acceptance of changes away from the status quo and cost - two features of all stated preference applications which economists are likely to involved with. More specifically, we show that agreeableness, openness, and conscientiousness all have an important role to play in shaping concerns about the environment. Focusing on the effects of personality within stated preferences may help achieve a better understanding of how acceptance of environmental improvement policies varies across people, of the distribution of benefits and costs across personality within a population, and highlight possible behavioural difficulties in implementing such environmental improvements. Finally, our research highlights that two individuals, having similar WTP values for a given environmental change, may have arrived at these values for different behavioural motivations. This enriches explanations of why the demand for environmental goods varies across people (Boyce, Wood and Ferguson, 2016b). 


\section{References}

Almlund, M., Duckworth, A. L., Heckman, J., and Kautz, T., 2011. Chapter 1 - Personality Psychology and Economics. In: Handbook of the Economics of Education, E. A. Hanushek, S. Machin, and L. Woessmann, eds., Elsevier, 1-181.

Ameriks, J., Caplin, A., and Leahy, J., 2003. Wealth Accumulation and the Propensity to Plan*. The Quarterly Journal of Economics, 118(3):1007-1047.

Ameriks, J., Caplin, A., Leahy, J., and Tyler, T., 2007. Measuring Self-Control Problems. The American Economic Review, 97(3):966-972.

Barbier, E. B., Czajkowski, M., and Hanley, N., 2017. Is the income elasticity of the willingness to pay for pollution control constant? Environmental and Resource Economics, 68(3):663-682.

Barrick, M. R., Mount, M. K., and Strauss, J. P., 1993. Conscientiousness and performance of sales representatives: Test of the mediating effects of goal setting. Journal of Applied Psychology, 78(5):715-722.

Ben-Akiva, M., McFadden, D., Train, K., Walker, J., Bhat, C., Bierlaire, M., Bolduc, D., Boersch-Supan, A., Brownstone, D., Bunch, D., Daly, A., De Palma, A., Gopinath, D., Karlstrom, A., and Munizaga, M., 2002. Hybrid Choice Models: Progress and Challenges. Marketing Letters, 13(3):163-175.

Bhat, C. R., Varin, C., and Ferdous, N., 2010. A comparison of the maximum simulated likelihood and composite marginal likelihood estimation approaches in the context of the multivariate ordered-response model. In: Advances in Econometrics, W. Greene and R. C. Hill, eds., Emerald Group Publishing Limited, 65-106.

Borghans, L., Duckworth, A. L., Heckman, J. J., and Weel, B. t., 2008. The Economics and Psychology of Personality Traits. Journal of Human Resources, 43(4):972-1059.

Boxall, P., and Adamowicz, W., 2002. Understanding Heterogeneous Preferences in Random Utility Models: A Latent Class Approach. Environmental and Resource Economics, 23(4):421-446.

Boyce, C. J., and Wood, A. M., 2011a. Personality and the marginal utility of income: Personality interacts with increases in household income to determine life satisfaction. Journal of Economic Behavior \& Organization, 78(1-2):183-191.

Boyce, C. J., and Wood, A. M., 2011b. Personality Prior to Disability Determines Adaptation. Psychological Science, 22(11):1397-1402.

Boyce, C. J., Wood, A. M., and Brown, G. D. A., 2010. The dark side of conscientiousness: Conscientious people experience greater drops in life satisfaction following unemployment. Journal of Research in Personality, 44(4):535-539.

Boyce, C. J., Wood, A. M., and Ferguson, E., 2016a. For better or for worse: The moderating effects of personality on the marriage-life satisfaction link. Personality and Individual Differences, 97:61-66.

Boyce, C. J., Wood, A. M., and Ferguson, E., 2016b. Individual Differences in Loss Aversion. Personality and Social Psychology Bulletin, 42(4):471-484.

Budziński, W., and Czajkowski, M. (2017). "Addressing measurement error and endogeneity in hybrid choice models." In: 23rd Annual Conference of the European Association of Environmental and Resource Economists, April 3-5, Athens, Greece.

Carson, R. T., and Groves, T., 2007. Incentive and informational properties of preference questions. Environmental and Resource Economics, 37(1):181-210. 
Chamorro-Premuzic, T., Bennett, E., and Furnham, A., 2007. The happy personality: Mediational role of trait emotional intelligence. Personality and Individual Differences, 42(8):1633-1639.

Chernev, A., 2004. Goal Orientation and Consumer Preference for the Status Quo. Journal of Consumer Research, 31(3):557-565.

Costa, P. T., McCrae, R. R., and Dye, D. A., 1991. Facet Scales for Agreeableness and Conscientiousness: A Revision of the NEO Personality Inventory. Personality and Individual Differences, 12(9):887-898.

Costa, P. T. J., and McCrae, R. R., 2008. The Revised NEO Personality Inventory (NEO-PI-R). In: The SAGE Handbook of Personality Theory and Assessment: Personality Measurement and Testing, G. J. Boyle, G. Matthews, and D. H. Saklofske, eds., SAGE Publications Ltd., Los Angeles, CA, USA.

Czajkowski, M., and Budziński, W., 2017. Simulation error in maximum likelihood estimation of discrete choice models. Working Paper 18/2017 (247), Department of Economics, University of Warsaw, Poland.

Czajkowski, M., Hanley, N., and Nyborg, K., 2017. Social Norms, Morals and Self-interest as Determinants of Pro-environment Behaviours: The Case of Household Recycling. Environmental and Resource Economics, 66:647-670.

Czajkowski, M., Vossler, C. A., Budziński, W., Wiśniewska, A., and Zawojska, E., 2017. Addressing empirical challenges related to the incentive compatibility of stated preference methods. Journal of Economic Behavior and Organization, 142:47-63.

Egan, M., Daly, M., Delaney, L., Boyce, C. J., and Wood, A. M., forthcoming. Adolescent Conscientiousness Predicts Lower Lifetime Unemployment. The Journal of Applied Psychology.

Faccioli, M., Czajkowski, M., Glenk, K., and Martin-Ortega, J., 2018. Environmental attitudes and place identity as simultaneous determinants of preferences for environmental goods. Working Paper 8/2018 (267), Faculty of Economic Sciences, University of Warsaw, Poland.

Farizo, B. A., Oglethorpe, D., and Soliño, M., 2016. Personality traits and environmental choices: On the search for understanding. Science of The Total Environment, 566567:157-167.

Fletcher, J. M., 2013. The effects of personality traits on adult labor market outcomes: Evidence from siblings. Journal of Economic Behavior \& Organization, 89:122-135.

George, J. M., and Zhou, J., 2001. When openness to experience and conscientiousness are related to creative behavior: an interactional approach. Journal of Applied Psychology, 86(3):513.

Gosling, S. D., Rentfrow, P. J., and Swann, W. B. J., 2003. A very brief measure of the Big-Five personality domains. Journal of Research in Personality, 37(6):504-528.

Grebitus, C., Lusk, J. L., and Nayga, R. M., Jr, 2013. Explaining differences in real and hypothetical experimental auctions and choice experiments with personality. Journal of Economic Psychology, 36:11-26.

Greene, W. H., 2017. Econometric Analysis. 8 Ed., Pearson, Upper Saddle River, NJ.

Hanley, N., and Barbier, E. B., 2009. Pricing Nature. Cost-Benefit Analysis and Environmental Policy. Edward Elgar, Edward Elgar, Cheltenham, UK and Northampton, MA, USA. 
Hanley, N., and Czajkowski, M., 2017. Stated Preference valuation methods: an evolving tool for understanding choices and informing policy. University of Warsaw, Department of Economics Working Paper 1(230).

Hartley, C. A., and Phelps, E. A., 2012. Anxiety and Decision-Making. Biological Psychiatry, 72(2):113-118.

Heller, D., Komar, J., and Lee, W. B., 2007. The Dynamics of Personality States, Goals, and Well-Being. Personality and Social Psychology Bulletin, 33(6):898-910.

Hensher, D. A., Rose, J. M., and Greene, W. H., 2015. Applied Choice Analysis. 2 Ed., Cambridge University Press, Cambridge, UK.

Hess, S., and Beharry-Borg, N., 2012. Accounting for Latent Attitudes in Willingness-to-Pay Studies: The Case of Coastal Water Quality Improvements in Tobago. Environmental and Resource Economics, 52(1):109-131.

Hirsh, J. B., 2010. Personality and environmental concern. Journal of Environmental Psychology, 30(2):245-248.

Hirsh, J. B., 2014. Environmental sustainability and national personality. Journal of Environmental Psychology, 38:233-240.

John, O. P., Robins, R. W., and Pervin, L. A., 2008. Handbook of Personality. 3'rd Ed., Guilford Press.

Johnston, R. J., Boyle, K. J., Adamowicz, W., Bennett, J., Brouwer, R., Cameron, T. A., Hanemann, W. M., Hanley, N., Ryan, M., Scarpa, R., Tourangeau, R., and Vossler, C. A., 2017. Contemporary Guidance for Stated Preference Studies. Journal of the Association of Environmental and Resource Economists, 4(2):319-405.

Judge, T. A., and Ilies, R., 2002. Relationship of personality to performance motivation: a metaanalytic review. Journal of Applied Psychology, 87(4):797.

Kahneman, D., Knetsch, J. L., and Thaler, R. H., 1991. Anomalies: The Endowment Effect, Loss Aversion, and Status Quo Bias. The Journal of Economic Perspectives, 5(1):193-206.

Karlõševa, A., Nõmmann, S., Nõmmann, T., Urbel-Piirsalu, E., Budziński, W., Czajkowski, M., and Hanley, N., 2016. Marine trade-offs: comparing the benefits of off-shore wind farms and marine protected areas. Energy Economics, 55:127-134.

Kesavayuth, D., Rosenman, R. E., and Zikos, V., 2016. RETIREMENT, PERSONALITY, AND WELL-BEING. Economic Inquiry, 54(2):733-750.

Lee, K., Ashton, M. C., Ogunfowora, B., Bourdage, J. S., and Shin, K.-H., 2010. The personality bases of socio-political attitudes: The role of Honesty-Humility and Openness to Experience. Journal of Research in Personality, 44(1):115-119.

Manski, C. F., 1977. The structure of random utility models. Theory and Decision, 8(3):229-254.

Mariel, P., and Meyerhoff, J., 2016. Hybrid discrete choice models: Gained insights versus increasing effort. Science of The Total Environment, 568:433-443.

Markowitz, E. M., Goldberg, L. R., Ashton, M. C., and Lee, K., 2012. Profiling the "ProEnvironmental Individual": A Personality Perspective. Journal of Personality, 80(1):81111.

McCrae, R. R., and Costa, P. T., 2008. A five-factor theory of personality. In: Handbook of personality: Theory and research, O. P. John, R. W. Robins, and L. A. Pervin, eds., Guilford Press, 139-153.

McCrae, R. R., and Sutin, A. R., 2009. Openness to experience. In: Handbook of Individual Differences in Social Behavior, M. R. Leary and R. H. Hoyle, eds., Guilford Press, New York, NY, US, 257-273. 
McFadden, D., 1974. Conditional Logit Analysis of Qualititative Choice Behaviour. In: Frontiers in Econometrics, P. Zarembka, ed., Academic Press, New York, NY, 105-142.

Milfont, T. L., and Sibley, C. G., 2012. The big five personality traits and environmental engagement: Associations at the individual and societal level. Journal of Environmental Psychology, 32(2):187-195.

Milon, J. W., and Scrogin, D., 2006. Latent preferences and valuation of wetland ecosystem restoration. Ecological Economics, 56(2):162-175.

Morey, E. R., and Thiene, M., 2017. Can Personality Traits Explain Where and With Whom You Recreate? A Latent-Class Site-Choice Model Informed by Estimates From Mixed-Mode LC Cluster Models With Latent-Personality Traits. Ecological Economics, 138:223-237.

Mueller, G., and Plug, E., 2006. Estimating the Effect of Personality on Male and Female Earnings. ILR Review, 60(1):3-22.

Nettle, D., 2006. The evolution of personality variation in humans and other animals. American Psychologist, 61(6):622.

Nunes, P. A. L. D., 2002. Using factor analysis to identify consumer preferences for the protection of a natural area in Portugal. European Journal of Operational Research, 140(2):499-516.

Nunes, P. A. L. D., and Schokkaert, E., 2003. Identifying the Warm Glow Effect in Contingent Valuation. Journal of Environmental Economics and Management, 45(2):231-245.

Nyhus, E. K., and Pons, E., 2005. The effects of personality on earnings. Journal of Economic Psychology, 26(3):363-384.

Onofri, L., and Nunes, P. A. L. D., 2014. De rationibus est disputandum: Psychological dimensions of choice and public policy design. Ecosystem Services, 10:172-179.

Ozer, D. J., and Benet-Martínez, V., 2006. Personality and the Prediction of Consequential Outcomes. Annual Review of Psychology, 57:401-421.

Pakalniete, K., Aigars, J., Czajkowski, M., Strake, S., Zawojska, E., and Hanley, N., 2017. Understanding the distribution of economic benefits from improving coastal and marine ecosystems. Science of The Total Environment, 584-585:29-40.

Renner, W., 2003. Human values: a lexical perspective. Personality and Individual Differences, 34(1):127-141.

Roberts, B. W., and Robins, R. W., 2000. Broad Dispositions, Broad Aspirations: The Intersection of Personality Traits and Major Life Goals. Personality and Social Psychology Bulletin, 26(10):1284-1296.

Rustichini, A., DeYoung, C. G., Anderson, J. C., and Burks, S. V., 2012. Toward the integration of personality theory and decision theory in the explanation of economic and health behavior. SSRN Scholarly Paper ID 2119057, Rochester, NY.

Salomon, I., and Ben-Akiva, M., 1983. The Use of the Life-Style Concept in Travel Demand Models. Environment and Planning A, 15(5):623-638.

Samuelson, W., and Zeckhauser, R. J., 1988. Status Quo Bias in Decision Making. Journal of Risk \& Uncertainty, 1(1):7-59.

Scarpa, R., and Rose, J. M., 2008. Design Efficiency for Non-Market Valuation with Choice Modelling: How to Measure it, What to Report and Why. Australian Journal of Agricultural and Resource Economics, 52(3):253-282.

Schokkaert, E., and Van Ootegem, L., 1990. Sen's Concept of the Living Standard Applied to the Belgian Unemployed. Recherches économiques de Louvain/Louvain Economic Review, 56:429-450. 
Swami, V., Chamorro-Premuzic, T., Snelgar, R., and Furnham, A., 2011. Personality, individual differences, and demographic antecedents of self-reported household waste management behaviours. Journal of Environmental Psychology, 31(1):21-26.

Thaler, R. H., and Sunstein, C. R., 2009. Nudge: Improving Decisions About Health, Wealth, and Happiness. HeinOnline, New York.

Train, K. E., 2009. Discrete Choice Methods with Simulation. 2 Ed., Cambridge University Press, New York.

Train, K. E., and Weeks, M., 2005. Discrete Choice Models in Preference Space and Willingness-to-pay Space. In: Applications of Simulation Methods in Environmental and Resource Economics, R. Scarpa and A. Alberini, eds., Springer, Dordrecht, 1-16.

Tuhkanen, H., Piirsalu, E., Nõmmann, T., Karlõševa, A., Nõmmann, S., Czajkowski, M., and Hanley, N., 2016. Valuing the benefits of improved marine environmental quality under multiple stressors. Science of The Total Environment, 551-552:367-375.

Uysal, S. D., and Pohlmeier, W., 2011. Unemployment duration and personality. Journal of Economic Psychology, 32(6):980-992.

Westmaas, J., Moeller, S., and Woicik, P. B., 2007. Validation of a Measure of College Students' Intoxicated Behaviors: Associations With Alcohol Outcome Expectancies, Drinking Motives, and Personality. Journal of American College Health, 55(4):227-237.

Winter, D. G., and Barenbaum, N. B., 1999. History of Modern Personality Theory and Research. In: Handbook of Personality: Theory and Research, L. A. Pervin and O. P. John, eds., Guilford Press, New York, NY, US, 3-27.

Wood, A. M., and Boyce, C., forthcoming. Developing, evaluating and using subjective scales of personality, preferences, and well-being: A guide to psychometrics for psychologists and economists. In: Economic psychology: the science of economic mental life and behaviour, R. Ranyard, ed., Wiley, Chichester, UK.

Wood, A. M., and Boyce, C. J., 2014. Personality, an Overview. In: Encyclopedia of Quality of Life Research, A. C. Michalos, ed., Springer, Dordrecht, Netherlands, 4773-47775. 


\section{Appendix 1. Technical details of the hybrid mixed logit model}

Discrete choice modelling is based on the random utility model (McFadden, 1974). In this framework, the utility function of consumer $i$ from choosing alternative $j$ at choice situation $t$ can be expressed as:

$$
U_{i j t}=\mathbf{x}_{i j t} \boldsymbol{\beta}+\varepsilon_{i j t},
$$

where $\boldsymbol{\beta}$ is the vector of utility parameters, $\mathbf{x}$ is the vector of alternative-specific attributes, and $\varepsilon$ is the random component, representing the joint influence of all unobserved factors that influence decision-making (Manski, 1977). By assuming that the random component is standard type-1 extreme value distributed, the multinomial logit (MNL) model is obtained with convenient closed-form expression for the choice probability:

$$
P(j \mid J)=\frac{\exp \left(\mathbf{x}_{i j t} \boldsymbol{\beta}\right)}{\sum_{k=1}^{J} \exp \left(\mathbf{x}_{i k t} \boldsymbol{\beta}\right)}
$$

In what follows, we apply a mixed logit (MXL) extension of the model, which allows to take the respondents' preference heterogeneity into account, as it has been shown to substantially improve model performance. In the MXL model preference parameters are individual-specific, following an a priori specified multivariate distribution $\boldsymbol{\beta}_{i} \square f(\mathbf{b}, \boldsymbol{\Sigma})$ where $\mathbf{b}$ is a vector of population means and $\boldsymbol{\Sigma}$ represents a (possibly non-diagonal) variance-covariance matrix. By assuming a structured variation of individual tastes in the sample, in the form of individual-based parameters, the MXL model is more realistic and typically yields a much better fit to the data (Hensher, Rose and Greene, 2015). This comes at the cost of a more complicated estimation procedure, however; the unconditional probability of individual $i$ choosing alternative $j$ in situation $t$ is an integral of standard logit probabilities over a density individual utility parameters (Train, 2009).

In our HMXL model we also assume that the random parameters $\boldsymbol{\beta}_{i}$ depend on a vector of latent variables $\mathbf{L} \mathbf{V}_{i}$, corresponding to respondents' personality traits. The functional form of this dependence is of the form: 


$$
\boldsymbol{\beta}_{i}=\Lambda^{\prime} \mathbf{L} \mathbf{V}_{i}+\boldsymbol{\beta}_{i}^{*}
$$

where $\boldsymbol{\Lambda}$ is a matrix of estimable coefficients and $\boldsymbol{\beta}_{i}^{*}$ has a multivariate normal distribution with a vector of means and a covariance matrix to be estimated. ${ }^{5}$

As a result, the conditional probability of individual $i$ 's choices in choice set $t$ is given by:

$$
P\left(y_{i} \mid \mathbf{X}_{i}, \boldsymbol{\beta}_{i}^{*}, \mathbf{L} \mathbf{V}_{i}, \boldsymbol{\Lambda}, \mathbf{b}, \boldsymbol{\Sigma}\right)=\prod_{t=1}^{T_{i}} \frac{\exp \left(\boldsymbol{X}_{i j t} \boldsymbol{\beta}_{i}\right)}{\sum_{k=1}^{C} \exp \left(\boldsymbol{X}_{i k t} \boldsymbol{\beta}_{i}\right)}
$$

The latent variables are also linked to the measurement component of the model, in which each of the five personality traits is measured using two seven-point Likert scale questions. The measurement equations are modelled using ordered probit. The measurement component of the model can be specified as follows:

$$
\mathbf{I}_{i}^{*}=\boldsymbol{\Gamma}^{\prime} \mathbf{L} \mathbf{V}_{i}+\boldsymbol{\eta}_{i}
$$

where $\mathbf{I}_{i}$ represents a vector of (ordered) indicator variables, $\boldsymbol{\Gamma}$ is a matrix of coefficients and $\boldsymbol{\eta}_{i}$ denotes a vector of error terms assumed to come from a multivariate normal distribution with zero means and an identity covariance matrix. ${ }^{6}$ Under this specification, the relationship between $I_{i l}$ and $I_{i l}^{*}$ (for the $l$-th indicator variable which takes $J$ possible, ordered values) becomes:

$$
\begin{array}{ccc}
I_{i l}=1, & \text { if } & I_{i l}^{*}<\alpha_{1 l} \\
\vdots & \vdots & \vdots \\
I_{i l}=k, & \text { if } & \alpha_{k-1 l} \leq I_{i l}^{*}<\alpha_{k l}, \\
\vdots & \vdots & \vdots \\
I_{i l}=J, & \text { if } & \alpha_{J-1 l} \leq I_{i l}^{*}
\end{array}
$$

\footnotetext{
${ }^{5}$ The number of columns in $\Lambda$ is equal to the number of latent variables and the number of rows equal to the number of non-monetary attributes.

${ }^{6}$ It is important to note that the number of measurement equations need not equal the number of latent variables. For instance, cases may arise where more than one indicator for a latent variable may be available. This framework can accommodate such a setting by specifying multiple measurement equations for a single latent variable.
} 
where the $\alpha$ 's are the threshold parameters to be estimated for each indicator. This specification leads to the well-known ordered probit likelihood form for $I_{i}$ :

$$
P\left(I_{i} \mid \mathbf{L} \mathbf{V}_{i}, \boldsymbol{\Gamma}, \boldsymbol{\alpha}\right)=\prod_{l=1}^{L}\left(P\left(I_{i l} \mid \mathbf{L} \mathbf{V}_{i}, \boldsymbol{\Gamma}_{l}, \alpha_{l}\right)\right)=\prod_{l=1}^{L}\left(\Phi\left(\alpha_{k l}-\boldsymbol{\Gamma}_{l}^{\prime} \mathbf{L} \mathbf{V}_{i}\right)-\Phi\left(\alpha_{k-1 l}-\boldsymbol{\Gamma}_{l}^{\prime} \mathbf{L} \mathbf{V}_{i}\right)\right),(2)
$$

where denotes the normal cdf, $\Gamma_{l}$ and $\alpha_{l}$ are the $l$-th row of the $\Gamma$ matrix and the vector of the threshold parameters for the $l$-th indicator variable, respectively. ${ }^{7}$

Combining equations (2), (2) and (2), we obtain the full-information likelihood function for our HMXL model, where for ease of exposition we stack the parameter vectors $\mathbf{b}, \boldsymbol{\Sigma}, \boldsymbol{\Lambda}, \boldsymbol{\Gamma}, \boldsymbol{\alpha}$ into the single vector $\boldsymbol{\Omega}$ :

$$
L_{i}=\int P\left(\mathbf{y}_{i} \mid \mathbf{X}_{i}, \boldsymbol{\beta}_{i}^{*}, \boldsymbol{\Omega}, \mathbf{L} \mathbf{V}_{i}\right) P\left(\mathbf{I}_{i} \mid \mathbf{\Omega}, \mathbf{L} \mathbf{V}_{i}\right) f\left(\boldsymbol{\beta}_{i}^{*}, \mathbf{L} \mathbf{V}_{i} \mid \mathbf{b}, \boldsymbol{\Sigma}\right) d\left(\boldsymbol{\beta}_{i}^{*}, \mathbf{L} \mathbf{V}_{i}\right)
$$

As random disturbances of $\boldsymbol{\beta}_{i}^{*}$, as well as latent variables $\mathbf{L} \mathbf{V}_{i}$ are not directly observed, they must be integrated out of the conditional likelihood. This multidimensional integral can be approximated using a simulated maximum likelihood approach. ${ }^{8}$

\footnotetext{
${ }^{7}$ Note that this likelihood is a factor of likelihoods of each indicator separately. It is so due to the earlier assumption that $\boldsymbol{\eta}_{i}$ has an identity covariance matrix. This assumption is equivalent to assuming that whole correlation between indicator variables is explained by the latent variables used. However, this assumption can be relaxed, as in Bhat, $\underline{\text { Varin and Ferdous (2010). }}$

${ }^{8}$ The models were estimated in Matlab using maximum simulated likelihood method with 10,000 scrambled Sobol draws (Czajkowski and Budziński, 2017). The software used here (estimation package for hybrid choice models) is available from github.com/czaj/DCE under CC BY 4.0 license.
} 
Appendix 2. Detailed estimation results - status quo and cost interacted with latent personality $\underline{\text { traits (all datasets) }}$

For each of the datasets we first present the results of the measurement component of the model, in which latent variables associated with personality traits are used as explanatory variables. This shows that our latent variables indeed represent the desired personality traits - the links with respective attitudinal questions are significant and of expected sign. As expected, we find that the absolute values of the coefficients often differ, indicating that the two attitudinal questions are not necessarily equally efficient at capturing each personality trait.

Next, the estimates of the utility function parameters follow. The estimated coefficients reflect marginal utilities associated with changes in the levels of the attributes, and as a result, changes in the probability of selecting an alternative. Consumers' preference heterogeneity is incorporated to the model by making the utility function parameters random. We assumed that the distribution of respondents' preferences for each attribute are normal (except log-normally distributed cost parameter, for which the coefficients of the underlying normal are presented) for this reason each attribute is associated with the estimate of the mean and standard deviation of its distribution in the population. Although the coefficients do not have a direct interpretation ${ }^{9}$ their signs reflect whether more of an attribute is perceived as good or bad while their relative values indicate their relative importance.

Finally, the mean of the distribution of preference parameters associated with Status quo and Cost was interacted with all latent variables corresponding to personality traits. ${ }^{10}$ This allows us to investigate, if preferences of respondents' who score high or low on one of the personality traits (i.e., have high or low values of the corresponding latent variable) differ from preferences of other respondents. Significance of the interaction terms indicates the existence of the link between a personality trait and preferences for a particular attribute, while the sign of the interaction coefficients reveals the direction of this preference difference.

This appendix does not include the estimated ordered probit threshold parameters and model diagnostics. They are available in the online supplement to this paper.

\footnotetext{
${ }^{9}$ Utility function is ordinal; the coefficients are confounded with the scale coefficient, because the variance of utility function error term is normalized.

${ }^{10}$ Note that each latent variable is normalized for 0 mean and unit standard deviation in order to facilitate interpretation and comparisons. Respondent with a latent variable value 0 is representing exactly the mean level of the corresponding personality trait, while respondent with a latent variable value 1 would be 1 standard deviation above the population mean, in terms of the strength of the corresponding personality trait. By normalization, we are able to compare which personality traits have relatively stronger influence.
} 
Table A2.1a. The measurement component of the HMXL model - Latvia

\begin{tabular}{|c|c|c|c|c|c|c|c|c|c|c|}
\hline I see myself as: & $\begin{array}{l}\text { Extraverted, } \\
\text { Enthusiastic }\end{array}$ & $\begin{array}{c}\text { Reserved, } \\
\text { Quiet }\end{array}$ & $\begin{array}{c}\text { Sympathetic, } \\
\text { Warm }\end{array}$ & $\begin{array}{c}\text { Critical, } \\
\text { Quarrelsome }\end{array}$ & $\begin{array}{c}\text { Dependable, } \\
\text { Self- } \\
\text { disciplined }\end{array}$ & $\begin{array}{l}\text { Disorganized, } \\
\text { Careless }\end{array}$ & $\begin{array}{c}\text { Anxious, } \\
\text { Easily upset }\end{array}$ & $\begin{array}{c}\text { Calm, } \\
\text { Emotionally } \\
\text { stable }\end{array}$ & $\begin{array}{l}\text { Open to new } \\
\text { experiences, } \\
\text { Complex }\end{array}$ & $\begin{array}{c}\text { Conventional, } \\
\text { Uncreative }\end{array}$ \\
\hline Extraversion & $\begin{array}{l}0.18 * * \\
(0.08)\end{array}$ & $\begin{array}{c}-0.16^{* *} \\
(0.07)\end{array}$ & & & & & & & & \\
\hline Agreeableness & & & $\begin{array}{c}0.61 * * * \\
(0.18)\end{array}$ & $\begin{array}{c}-0.21 * * * \\
(0.07)\end{array}$ & & & & & & \\
\hline Conscientiousness & & & & & $\begin{array}{c}0.60 * * * \\
(0.05)\end{array}$ & $\begin{array}{c}-3.10 * * \\
(1.35)\end{array}$ & & & & \\
\hline Neuroticism & & & & & & & $\begin{array}{l}1.38 * * \\
(0.59)\end{array}$ & $\begin{array}{c}-0.54 * * * \\
(0.11)\end{array}$ & & \\
\hline Openness To Experiences & & & & & & & & & $\begin{array}{c}0.49 * * * \\
(0.08)\end{array}$ & $\begin{array}{c}-0.29 * * * \\
(0.06)\end{array}$ \\
\hline
\end{tabular}

Table A2.1b. The discrete choice component of the HMXL model - Latvia

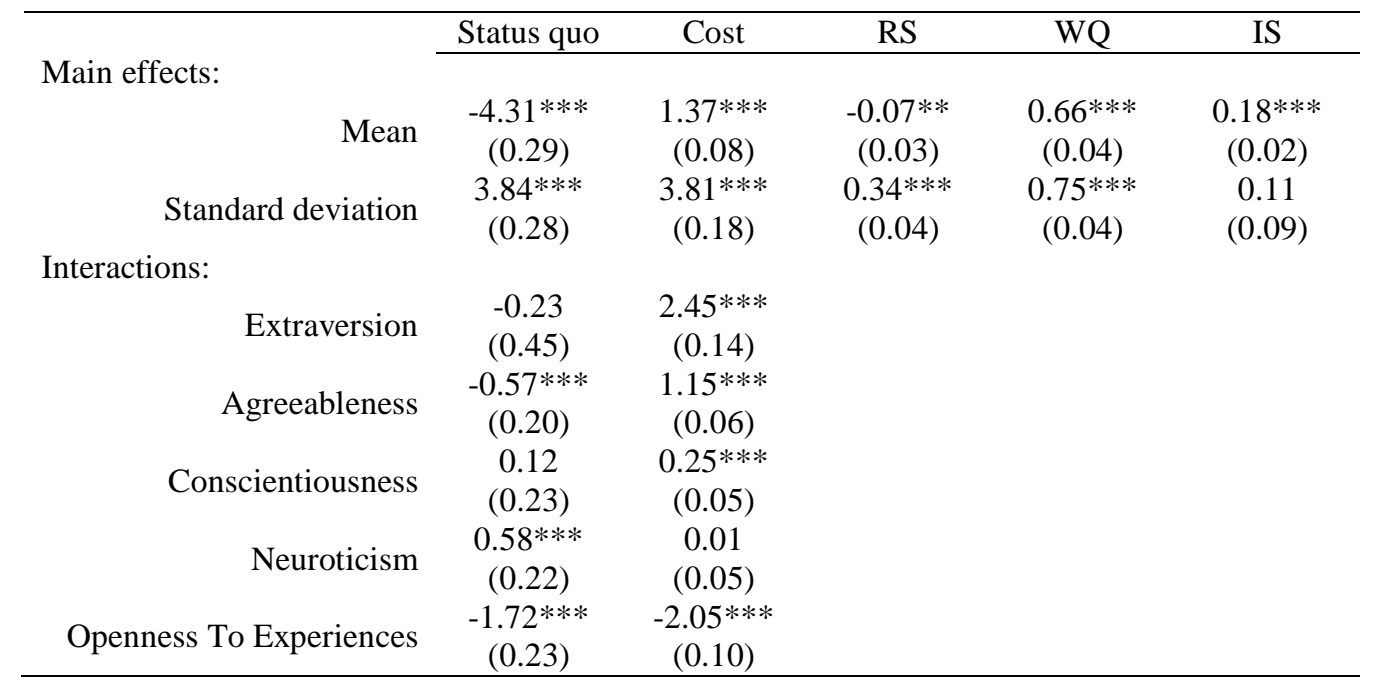

Notes: $* * *, * *$ and $*$ indicate significance at the level of $1 \%, 5 \%$, and $10 \%$, respectively. Standard errors (s.e.) are given in brackets. 
Table A2.2a. The measurement component of the HMXL model - Estonia 1

\begin{tabular}{|c|c|c|c|c|c|c|c|c|c|c|}
\hline I see myself as: & $\begin{array}{l}\text { Extraverted, } \\
\text { Enthusiastic }\end{array}$ & $\begin{array}{c}\text { Reserved, } \\
\text { Quiet }\end{array}$ & $\begin{array}{c}\text { Sympathetic, } \\
\text { Warm }\end{array}$ & $\begin{array}{c}\text { Critical, } \\
\text { Quarrelsome }\end{array}$ & $\begin{array}{c}\text { Dependable, } \\
\text { Self- } \\
\text { disciplined }\end{array}$ & $\begin{array}{l}\text { Disorganized, } \\
\text { Careless }\end{array}$ & $\begin{array}{c}\text { Anxious, } \\
\text { Easily upset }\end{array}$ & $\begin{array}{c}\text { Calm, } \\
\text { Emotionally } \\
\text { stable }\end{array}$ & $\begin{array}{l}\text { Open to new } \\
\text { experiences, } \\
\text { Complex }\end{array}$ & $\begin{array}{c}\text { Conventional, } \\
\text { Uncreative }\end{array}$ \\
\hline Extraversion & $\begin{array}{l}0.41 * * \\
(0.17)\end{array}$ & $\begin{array}{c}-0.47 * * \\
(0.20)\end{array}$ & & & & & & & & \\
\hline Agreeableness & & & $\begin{array}{c}0.27 \\
(0.24)\end{array}$ & $\begin{array}{l}-0.22 \\
(0.21)\end{array}$ & & & & & & \\
\hline Conscientiousness & & & & & $\begin{array}{c}0.83^{* *} \\
(0.36)\end{array}$ & $\begin{array}{c}-0.85^{* *} * \\
(0.37)\end{array}$ & & & & \\
\hline Neuroticism & & & & & & & $\begin{array}{c}5.48 \\
(3.97)\end{array}$ & $\begin{array}{c}-0.37 * * * \\
(0.06)\end{array}$ & & \\
\hline Openness To Experiences & & & & & & & & & $\begin{array}{l}0.62 * * \\
(0.24)\end{array}$ & $\begin{array}{c}-0.40 * * \\
(0.17)\end{array}$ \\
\hline
\end{tabular}

Table A2.2b. The discrete choice component of the HMXL model - Estonia 1

\begin{tabular}{|c|c|c|c|c|c|c|}
\hline & Status quo & Cost & FLS & PRS & WQ & IS \\
\hline \multicolumn{7}{|l|}{ Main effects: } \\
\hline Mean & $-4.33 * * *$ & -0.13 & $1.58 * * *$ & $1.13 * * *$ & $0.36 * * *$ & $0.69 * * *$ \\
\hline Miean & $(0.42)$ & $(0.38)$ & $(0.15)$ & $(0.11)$ & $(0.04)$ & $(0.09)$ \\
\hline Standard deviation & $3.85 * * *$ & $5.08 * * *$ & $1.38 * * *$ & $1.29 * * *$ & $0.37 * * *$ & $0.72 * * *$ \\
\hline Standard deviation & $(0.35)$ & $(0.41)$ & $(0.19)$ & $(0.14)$ & $(0.05)$ & $(0.13)$ \\
\hline \multicolumn{7}{|l|}{ Interactions: } \\
\hline \multirow{2}{*}{ Extraversion } & $-0.62 *$ & $0.31 * *$ & & & & \\
\hline & $(0.37)$ & $(0.15)$ & & & & \\
\hline \multirow{2}{*}{ Agreeableness } & 0.42 & $0.57 * * *$ & & & & \\
\hline & $(0.55)$ & $(0.21)$ & & & & \\
\hline \multirow{2}{*}{ Conscientiousness } & 0.06 & $0.36^{* *}$ & & & & \\
\hline & $(0.29)$ & $(0.15)$ & & & & \\
\hline \multirow{2}{*}{ Neuroticism } & 0.20 & 0.04 & & & & \\
\hline & $(0.28)$ & $(0.14)$ & & & & \\
\hline \multirow{2}{*}{ Openness To Experiences } & $-0.67 * *$ & -0.22 & & & & \\
\hline & $(0.32)$ & $(0.23)$ & & & & \\
\hline
\end{tabular}

Notes: $* * *, * *$ and $*$ indicate significance at the level of $1 \%, 5 \%$, and $10 \%$, respectively. Standard errors (s.e.) are given in brackets. 
Table A2.3a. The measurement component of the HMXL model - Estonia 2

\begin{tabular}{|c|c|c|c|c|c|c|c|c|c|c|}
\hline I see myself as: & $\begin{array}{l}\text { Extraverted, } \\
\text { Enthusiastic }\end{array}$ & $\begin{array}{l}\text { Reserved, } \\
\text { Quiet }\end{array}$ & $\begin{array}{l}\text { Sympathetic, } \\
\text { Warm }\end{array}$ & $\begin{array}{c}\text { Critical, } \\
\text { Quarrelsome }\end{array}$ & $\begin{array}{c}\text { Dependable, } \\
\text { Self- } \\
\text { disciplined }\end{array}$ & $\begin{array}{l}\text { Disorganized, } \\
\text { Careless }\end{array}$ & $\begin{array}{c}\text { Anxious, } \\
\text { Easily upset }\end{array}$ & $\begin{array}{c}\text { Calm, } \\
\text { Emotionally } \\
\text { stable } \\
\end{array}$ & $\begin{array}{l}\text { Open to new } \\
\text { experiences, } \\
\text { Complex }\end{array}$ & $\begin{array}{l}\text { Conventional, } \\
\text { Uncreative }\end{array}$ \\
\hline Extraversion & $\begin{array}{c}0.26^{* * * *} \\
(0.10)\end{array}$ & $\begin{array}{c}-0.35 * * * \\
(0.11)\end{array}$ & & & & & & & & \\
\hline Agreeableness & & & $\begin{array}{c}0.22 * * * \\
(0.08)\end{array}$ & $\begin{array}{c}-0.24 * * * \\
(0.07)\end{array}$ & & & & & & \\
\hline Conscientiousness & & & & & $\begin{array}{c}0.79 * * * \\
(0.13)\end{array}$ & $\begin{array}{c}-0.97 * * * \\
(0.18)\end{array}$ & & & & \\
\hline Neuroticism & & & & & & & $\begin{array}{c}0.61 * * * \\
(0.08)\end{array}$ & $\begin{array}{c}-1.47 * * * \\
(0.39)\end{array}$ & & \\
\hline Openness To Experiences & & & & & & & & & $\begin{array}{c}0.52 * * * \\
(0.09)\end{array}$ & $\begin{array}{c}-0.47 * * * \\
(0.08)\end{array}$ \\
\hline
\end{tabular}

Table A2.3b. The discrete choice component of the HMXL model - Estonia 2

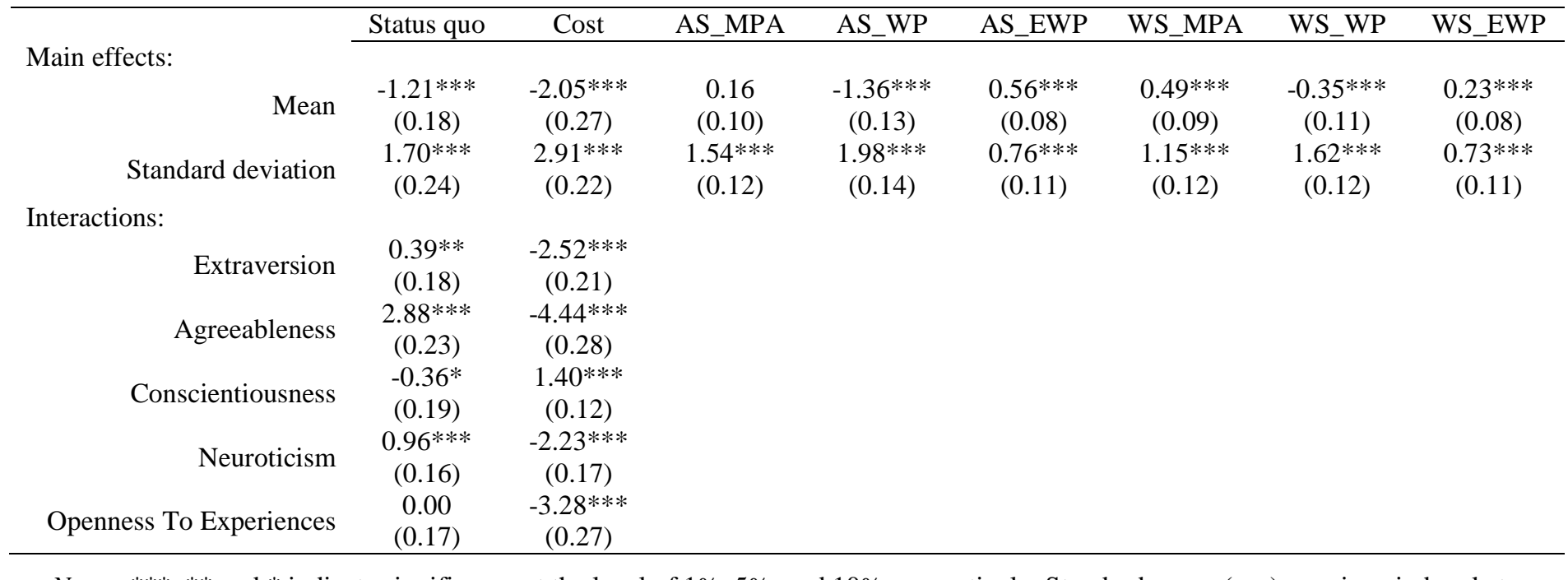

Notes: $* * * * *$ and $*$ indicate significance at the level of $1 \%, 5 \%$, and $10 \%$, respectively. Standard errors (s.e.) are given in brackets. 
Appendix 3. Detailed estimation results - all attributes interacted with latent personality traits (Estonia 1 dataset; WTP-space)

Table A3.1a. The measurement component of the HMXL model - Latvia

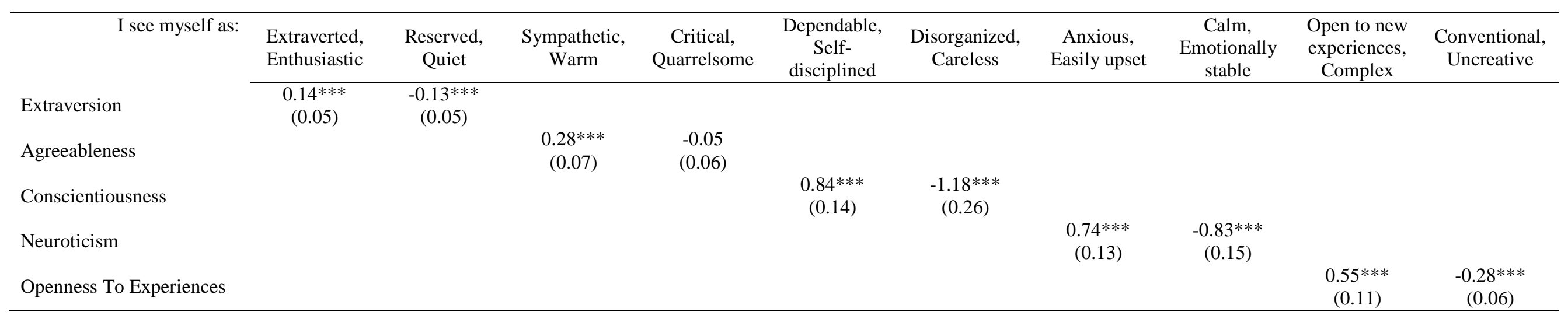

Table A3.1b. The discrete choice component of the HMXL model - Latvia

\begin{tabular}{|c|c|c|c|c|c|}
\hline & Status quo & Cost & $\mathrm{RS}$ & WQ & IS \\
\hline \multicolumn{6}{|l|}{ Main effects: } \\
\hline Mean & $\begin{array}{c}8.41 * * * \\
(0.81)\end{array}$ & $\begin{array}{c}-0.83 * * * \\
(0.07)\end{array}$ & $\begin{array}{l}-0.01 \\
(0.10)\end{array}$ & $\begin{array}{c}3.18 * * * \\
(0.20)\end{array}$ & $\begin{array}{c}0.46 * * * \\
(0.09)\end{array}$ \\
\hline & $55.20 * * *$ & 0.19 & $0.32 * * *$ & $1.04 * * *$ & 0.06 \\
\hline Standard deviation & (3.62) & $(0.21)$ & $(0.07)$ & $(0.12)$ & $(0.08)$ \\
\hline \multicolumn{6}{|l|}{ Interactions: } \\
\hline & $14.33^{* * *}$ & $1.12 * * *$ & $0.35 * * *$ & $-0.20 *$ & $-0.39 * * *$ \\
\hline Extraversion & (1.08) & $(0.07)$ & $(0.08)$ & $(0.11)$ & $(0.09)$ \\
\hline \multirow{2}{*}{ Agreeableness } & -0.56 & $0.49 * * *$ & $-0.61 * * *$ & $-3.27 * * *$ & $-0.19 *$ \\
\hline & $(0.38)$ & $(0.09)$ & $(0.12)$ & $(0.22)$ & $(0.11)$ \\
\hline \multirow{2}{*}{ Conscientiousness } & $0.41 *$ & 0.05 & -0.08 & $0.45 * * *$ & 0.13 \\
\hline & $(0.23)$ & $(0.11)$ & $(0.10)$ & $(0.13)$ & $(0.16)$ \\
\hline \multirow{2}{*}{ Neuroticism } & $-1.19 * * *$ & $-0.17 *$ & -0.07 & $0.24 * *$ & $0.20 * *$ \\
\hline & $(0.23)$ & $(0.09)$ & $(0.09)$ & $(0.11)$ & $(0.10)$ \\
\hline \multirow{2}{*}{ Openness To Experiences } & $-3.73 * * *$ & $-0.51 * * *$ & $0.33 * * *$ & $1.60 * * *$ & $0.26 * * *$ \\
\hline & $(0.40)$ & $(0.10)$ & $(0.11)$ & $(0.15)$ & $(0.08)$ \\
\hline
\end{tabular}

Notes: ***,** and * indicate significance at the level of $1 \%, 5 \%$, and $10 \%$, respectively. Standard errors (s.e.) are given in brackets. 
To what extent do you agree or disagree the given statements applied to yourself? Please mark, on your opinion, for each pair of traits in the table the most corresponding to you option. Please mark the extent to which each pair of traits applies to you, even if one characteristic applies more strongly than the other.

\begin{tabular}{|c|c|c|c|c|c|c|c|}
\hline I see myself as ... & Disagree fully & $\begin{array}{c}\text { Disagree } \\
\text { moderately }\end{array}$ & Disagree a little & $\begin{array}{c}\text { Neither agree nor } \\
\text { disagree }\end{array}$ & Agree a little & Agree moderately & Agree fully \\
\hline 1. extraverted, enthusiastic & 1 & 2 & 3 & 4 & 5 & 6 & 7 \\
\hline 2. critical, quarrelsome & 1 & 2 & 3 & 4 & 5 & 6 & 7 \\
\hline 3. dependable, self-disciplined & 1 & 2 & 3 & 4 & 5 & 6 & 7 \\
\hline 4. anxious, easily upset & 1 & 2 & 3 & 4 & 5 & 6 & 7 \\
\hline 5. open to new experiences, complex & 1 & 2 & 3 & 4 & 5 & 6 & 7 \\
\hline 6. reserved, quiet & 1 & 2 & 3 & 4 & 5 & 6 & 7 \\
\hline 7. sympathetic, warm & 1 & 2 & 3 & 4 & 5 & 6 & 7 \\
\hline 8. disorganized, careless & 1 & 2 & 3 & 4 & 5 & 6 & 7 \\
\hline 9. calm, emotionally stable & 1 & 2 & 3 & 4 & 5 & 6 & 7 \\
\hline 10. conventional, uncreative & 1 & 2 & 3 & 4 & 5 & 6 & 7 \\
\hline
\end{tabular}

